PNNL-20596

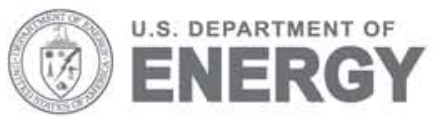

Prepared for the U.S. Department of Energy under Contract DE-AC05-76RL01830

\title{
Physics-Based Stress Corrosion Cracking Component Reliability Model cast in an R7-Compatible Cumulative Damage Framework
}

Draft Report Supporting Technology Inputs to the RiskInformed Safety Margin Characterization Pathway of the DOE Light Water Reactor Sustainability Program

Stephen D. Unwin

Kenneth I. Johnson

Robert F. Layton

Peter P. Lowry

Scott E. Sanborn

Mychailo B. Toloczko

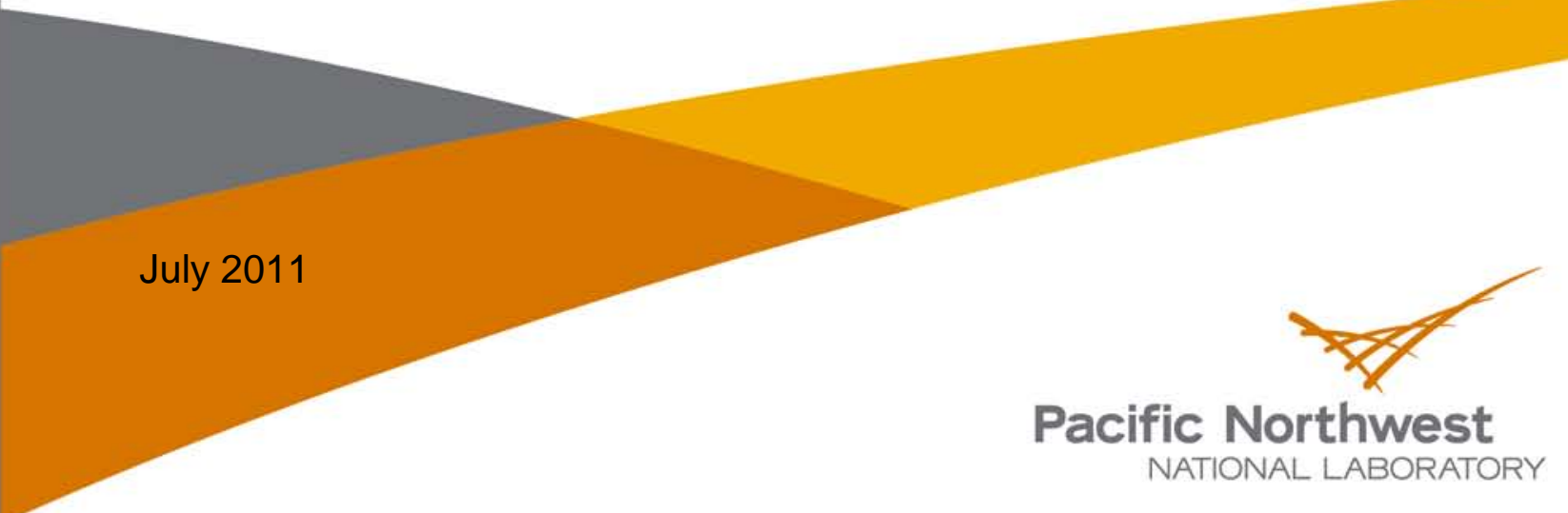




\title{
DISCLAIMER
}

This report was prepared as an account of work sponsored by an agency of the United States Government. Neither the United States Government nor any agency thereof, nor Battelle Memorial Institute, nor any of their employees, makes any warranty, express or implied, or assumes any legal liability or responsibility for the accuracy, completeness, or usefulness of any information, apparatus, product, or process disclosed, or represents that its use would not infringe privately owned rights. Reference herein to any specific commercial product, process, or service by trade name, trademark, manufacturer, or otherwise does not necessarily constitute or imply its endorsement, recommendation, or favoring by the United States Government or any agency thereof, or Battelle Memorial Institute. The views and opinions of authors expressed herein do not necessarily state or reflect those of the United States Government or any agency thereof.

\author{
PACIFIC NORTHWEST NATIONAL LABORATORY \\ operated by \\ BATTELLE \\ for the \\ UNITED STATES DEPARTMENT OF ENERGY \\ under Contract DE-AC05-76RL01830
}

Printed in the United States of America

$$
\begin{aligned}
& \text { Available to DOE and DOE contractors from the } \\
& \text { Office of Scientific and Technical Information, } \\
& \text { P.O. Box 62, Oak Ridge, TN 37831-0062; } \\
& \text { ph: (865) 576-8401 } \\
& \text { fax: (865) 576-5728 } \\
& \text { email: reports@adonis.osti.gov }
\end{aligned}
$$

Available to the public from the National Technical Information Service 5301 Shawnee Rd., Alexandria, VA 22312 ph: (800) 553-NTIS (6847)

email: orders@ntis.gov <http://www.ntis.gov/about/form.aspx> Online ordering: http://www.ntis.gov 


\section{Table of Contents}

Executive Summary............................................................ 4

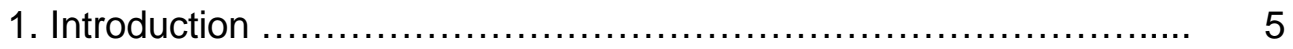

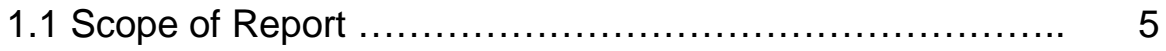

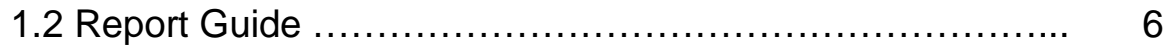

2. Component and Degradation Mechanism Selection ................ 8

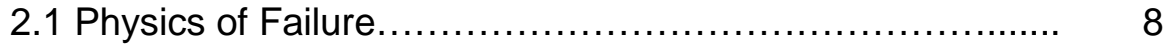

2.2 Degradation.............................................. 9

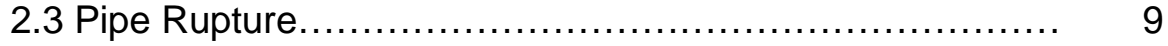

3. Multi-State Model............................................. 10

3.1 Initial State S....................................... 11

3.2 Micro-Crack State M................................. 11

3.3 Radial Macro-Crack State D........................... 11

3.4 Circumferential Macro-Crack State C..................... 12

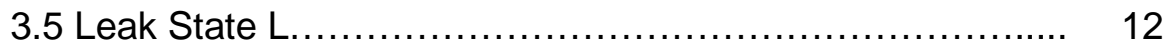

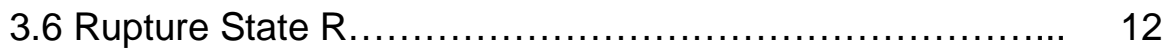

4. The Cumulative Degradation (Heartbeat) Framework............. 14

4.1 Framework Description................................ 14

4.2 Initial to Micro-Crack Transition: S to M................... 18

4.3 Micro-Crack to Radial or Circumferential Macro-Crack

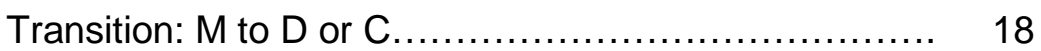

4.4 Radial Macro-Crack to Leak Transition: D to L............. 22

4.5 Transition to Rupture: R............................. 23

4.6 Repair Transitions: M to S, D to S, C to S, L to S............ 25

5. Model Implementation........................................ 27

6. References................................................. 29

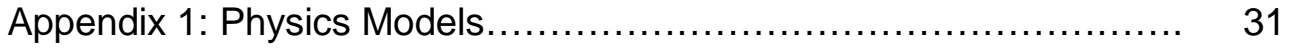

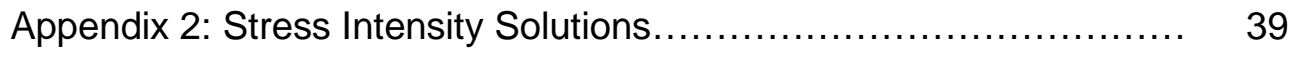




\section{EXECUTIVE SUMMARY}

The Risk-Informed Safety Margin Characterization (RISMC) pathway is a set of activities defined under the U.S. Department of Energy Light Water Reactor Sustainability Program. The overarching objective of RISMC is to support plant life-extension decision-making by providing a state-of-knowledge characterization of safety margins in key systems, structures, and components (SSCS). The methodology emerging from the RISMC pathway is not a conventional probabilistic risk assessment (PRA)-based one; rather, it relies on a reactor systems simulation framework in which physical conditions of normal reactor operations, as well as accident environments, are explicitly modeled subject to uncertainty characterization. RELAP 7 (R7) is the platform being developed at Idaho National Laboratory to model these physical conditions.

Adverse effects of aging systems could be particularly significant in those SSCs for which management options are limited; that is, components for which replacement, refurbishment, or other means of rejuvenation are least practical. These include various passive SSCs, such as piping components. Pacific Northwest National Laboratory is developing passive component reliability models intended to be compatible with the R7 framework. In the R7 paradigm, component reliability must be characterized in the context of the physical environments that R7 predicts. So, while conventional reliability models are parametric, relying on the statistical analysis of service data, RISMC reliability models must be physics-based and driven by the physical boundary conditions that $\mathrm{R} 7$ provides, thus allowing full integration of passives into the R7 multi-physics environment. The model must also be cast in a form compatible with the cumulative damage framework that $\mathrm{R} 7$ is being designed to incorporate.

\section{Figure ES-1. Multi-State Model of Dissimilar Metal Weld Stress Corrosion Cracking}

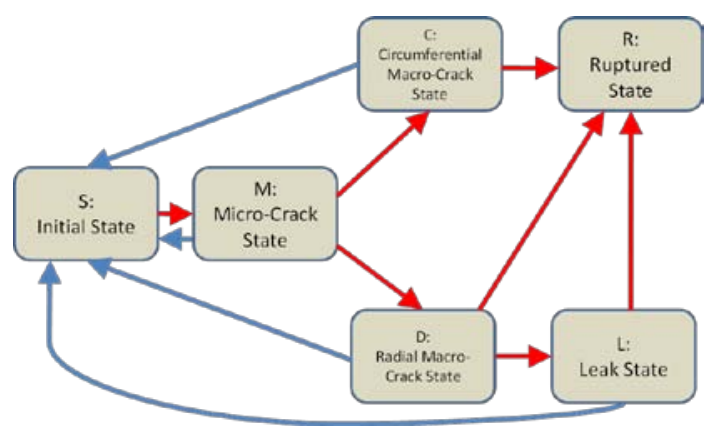

Primary water stress corrosion cracking (SCC) of reactor coolant system Alloy 82/182 dissimilar metal welds has been selected as the initial application for examining the feasibility of R7compatible physics-based cumulative damage models. This is a potentially risk-significant degradation mechanism in Class 1 piping because of its relevance to loss of coolant accidents. In this report a physics-based multi-state model is defined (Figure ES-1), which describes progressive degradations of dissimilar metal welds from micro-crack initiation to component rupture, while accounting for the possibility of interventions and repair. The cumulative damage representation of the multi-state model and its solutions are described, along with the conceptual means of integration into the R7 environment. 


\section{Introduction}

The Risk-Informed Safety Margin Characterization (RISMC) pathway is a set of activities defined under the U.S. Department of Energy (DOE) Light Water Reactor Sustainability Program [1]. The overarching objective of RISMC is to support plant life-extension decisionmaking by providing a state-of-knowledge characterization of safety margins in key systems, structures, and components (SSCs). A technical challenge at the core of this effort is to establish the conceptual and technical feasibility of analyzing safety margin in a risk-informed way, which, unlike conventionally defined deterministic margin analysis, is founded on probabilistic characterizations of SSC performance.

The anticipation is that probabilistic safety margins will in general entail the uncertainty characterization both of the prospective challenge to the performance of an SSC ("load") and of its "capacity" to withstand that challenge. In the context of long-term asset management and reactor life extension, those characterizations might be expected to depend on the age of the SSC, accounting for degrading SSC capacity, and potentially on increasing loads due to, say, power uprates. Therefore, in the establishment of safety margins intended to protect public safety in the long term, account of the effects of system aging will be essential.

\subsection{Scope of Report}

Adverse effects of aging would be particularly significant in those SSCs for which management options are limited; that is, components for which replacement, refurbishment, or other means of rejuvenation are least practical. These include various passive SSCs, such as piping components. In probabilistic risk assessment (PRA) models, passive SSCs appear as significant risk-contributors in the form of initiating events such as loss of coolant accidents and internal floods, and they are also the focus of plant fragility evaluation for seismic events. Furthermore, because of limited options for rejuvenation, passives may be expected to play an increasing role in long-term risk. Therefore, in the establishment of safety margins intended to ensure long-term safety, the effects and implications of SSC aging and degradation must be addressed.

The methodology paradigm being developed under the RISMC pathway is not a conventional PRA-based one. Rather, it is based on a reactor systems simulation framework in which physical conditions of normal reactor operations, as well as accident environments, are explicitly modeled subject to uncertainty characterization. The platform being developed to model these physical conditions is RELAP 7, or R7 [2, 3]. While a parallel effort is being undertaken to develop R7, this report documents progress on the development of models of passive component reliability that will ultimately be integrated into R7.

The models being developed under this task are not conventional component reliability models. In the R7 paradigm, component reliability must be characterized in the context of the physical environments that $\mathrm{R} 7$ predicts. So, while conventional reliability models are parametric and rely 
on the statistical analysis of service data, reliability models in the current context must be physics-based and driven by the physical boundary conditions R7 predicts, allowing full integration of passives models into the R7 multi-physics environment (see Figure 1-1). At the same time, the models need to accommodate elements of more conventional reliability models so that, for example, the effects of intervention strategies (inspection and repair) can be properly accounted for.

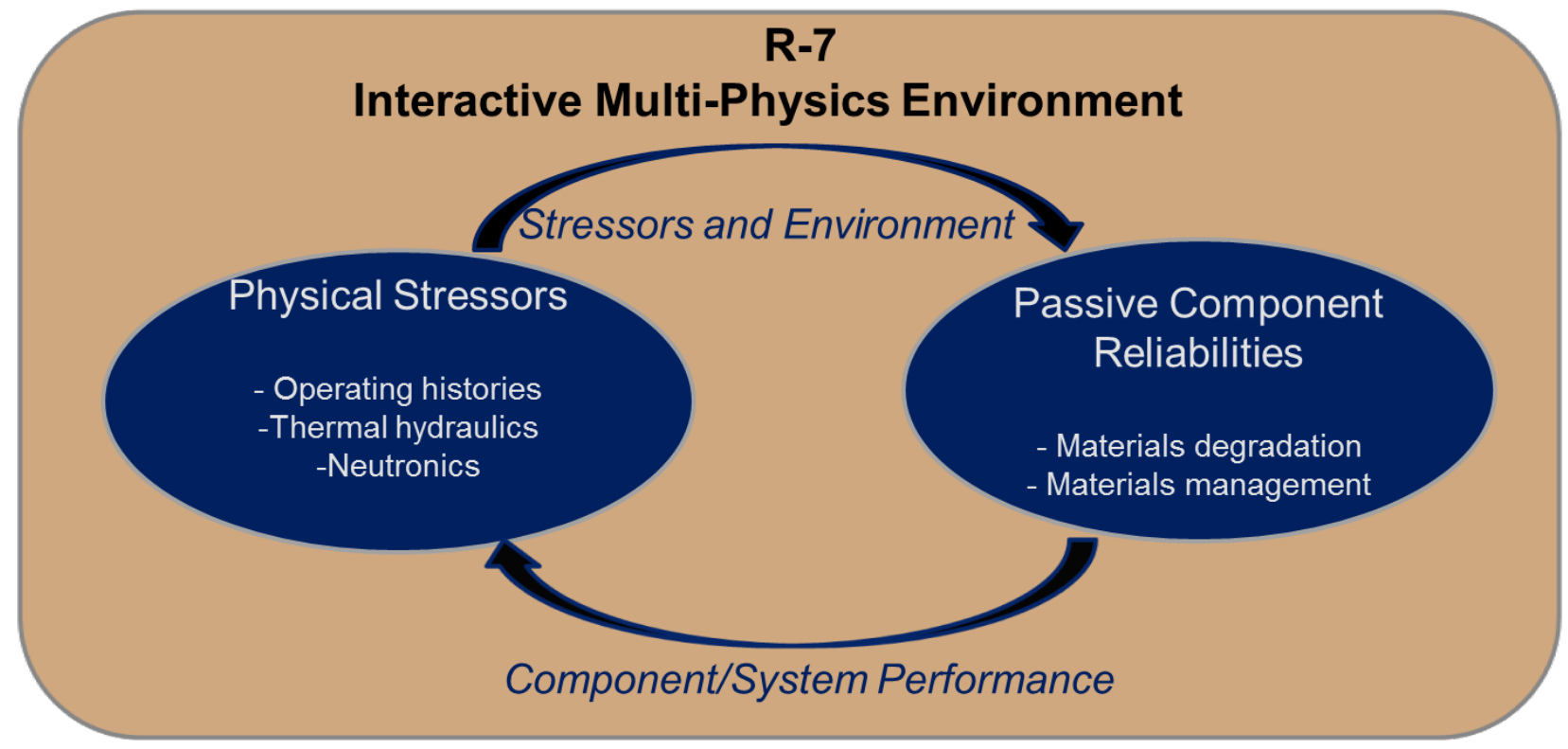

Figure 1-1 - Integration of passives in R7

In FY10, substantial progress was made on the development of physics-based multi-state models. These shared some features with parametric Markov models of component reliability, although the degradation transition rates were based on physics models of material degradation rather than on service data [4]. In FY11, progress has been made on R7 development and on the anticipated approach to the incorporation of passives reliability models. Therefore, much of the activity on passives model development in FY11 had focused on restructuring the multi-state models such that they are compatible with the evolving R7 paradigm. Specifically, the passives models are now being restructured in the cumulative damage framework. Significant progress has also been made in FY11 on expanding the scope of the physical phenomena incorporated into the multi-state models. This document reports FY11 progress on the development of R7compatible passives reliability models.

\subsection{Report Guide}

Section 2 describes the components and degradation mechanisms selected as the basis for methods development. The basic structure of the multi-state reliability model is described in Section 3. Section 4 describes the way in which the physics models (defined in detail in Appendices 1 and 2) are incorporated into the multi-state cumulative damage model framework. 
Physics-Based SCC Reliability Model in a Cumulative Damage Framework

Section 5 shows the structure of the outputs from the multi-state model, and references are listed in Section 6. 


\section{Component and Degradation Mechanism Selection}

\subsection{Physics of Failure}

Primary water stress corrosion cracking (SCC) of reactor coolant system Alloy 82/182 dissimilar metal welds has been selected as the initial application for examining the feasibility of R7compatible physics-based cumulative damage models. Alloy 82/182 welds are found in several key locations in Class 1 piping structures, such as the vessel reactor coolant pipe welds and pressurizer surge line pipe welds. This latter location is selected as our analysis case. Figure 21 shows a Westinghouse surge line nozzle with an Alloy 182 weld joining the stainless steel safe end to the low alloy steel nozzle. Cracks that form in these structures will grow from inner to outer diameter with one of two principal morphologies. These are represented in Figure 2-2. In the first of these the crack tends to grow primarily outward from the initiation site towards the outer diameter as shown in Figure 2-2A. We will refer to this as a radial crack. In the second, the crack grows relatively evenly around the circumference as shown in Figure 2-2B, potentially resulting in an SCC crack that can transition to rupture before a leak is detected. We will refer to this as a circumferential crack. Both these cracks morphologies can be associated with loss of coolant accidents.

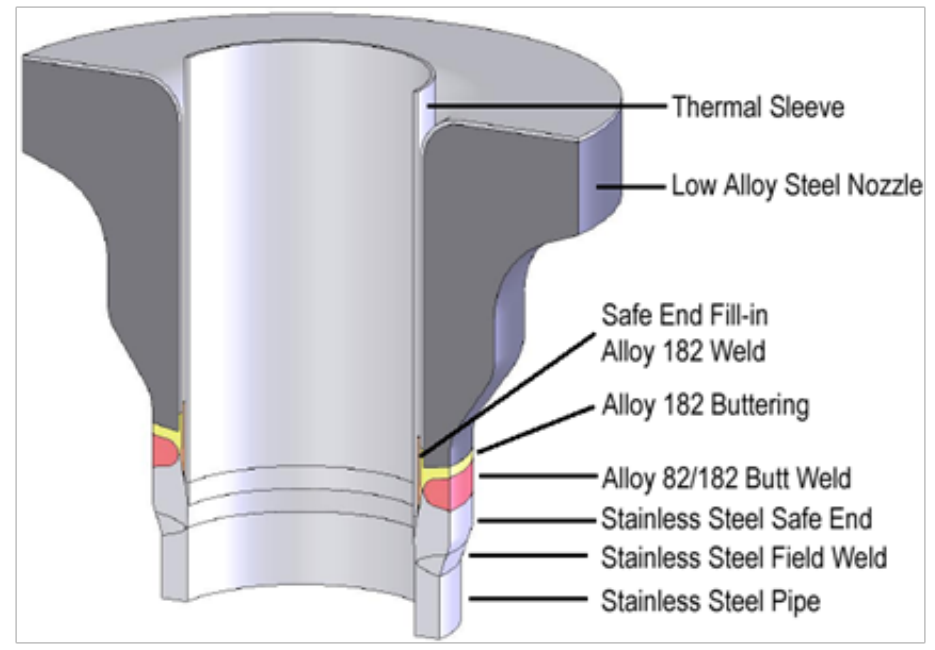

Figure 2-1

Layout of a Westinghouse PWR surge line nozzle connection to the pressurizer (Courtesy of Westinghouse). 


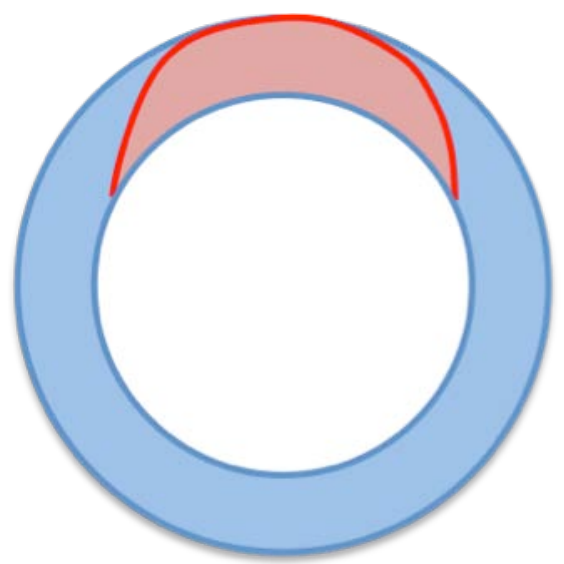

A

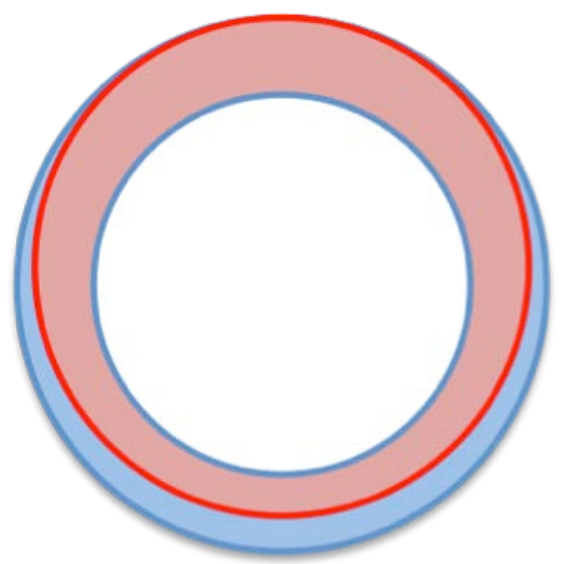

B

Figure 2-2 Two basic cross-flow crack morphologies: radial and circumferential.

\subsection{Degradation}

For our model, SCC is considered in Alloy 82/182 to be a two-step process consisting of (1) crack initiation, followed by (2) crack propagation. Similar to other nucleation and growth phenomena, SCC is generally modeled as, first, a nucleation step governed by statistical processes, and then as crack growth that has a more deterministic basis. The probability of nucleation is governed both by the presence of preexisting surface flaws in the material and the rate of formation of surface flaws due to the environment. Published models of crack initiation typically do not attempt to define initial flaw characteristics, since, because of the practical difficulty in identifying a surface flaw, such a model could not be implemented. As will be discussed, the Weibull distribution is the most common framework for quantifying SCC initiation probability [5-7].

Compared to SCC initiation, there are abundant data on SCC crack growth. Numerous laboratories have performed SCC crack growth testing on Alloys 182 and 82, and several organizations have published data compilations and accompanying phenomenological models of crack growth. These models are generally similar, and typically contain stress intensity and temperature dependences.

\subsection{Pipe Rupture}

Several models addressing criteria for pipe/weld failure are available [8]. They are generally based on estimation of weld failure pressure as a function of crack size, crack morphology and materials properties.

The physical models underlying these degradation and failure phenomena are described in Appendices 1 and 2, and the means of implementing the models in an R7-compatible cumulative damage environment are addressed in Section 4. 


\section{Multi-State Model}

The general structure of the physics-based multistate model of SCC was developed in FY10. A solution methodology was developed for the model and implemented in that year. However, R7 simulation concepts have evolved and FY11 activity have focused on developing solution methods that are fully compatible with the emerging R7 paradigms. These solution methods are described in Section 4. Figure 3-1 shows the structure of the multi-state model. In this section, the model states and transitions are defined.

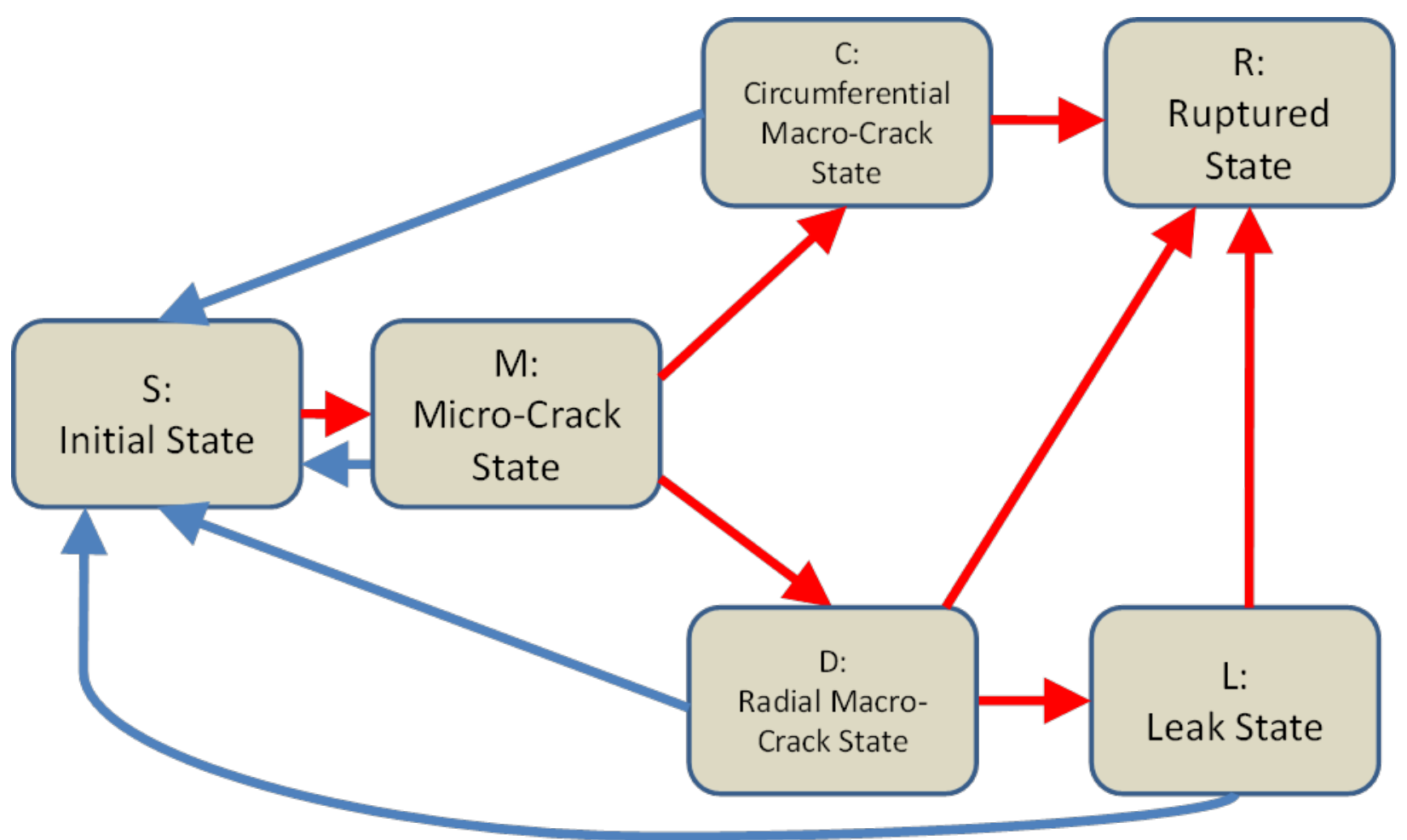

Figure 3-1 Physics Based Damage Model

The states of the model are:

$\mathrm{S}=$ Initial state (with possible presence of undetectable flaws)

$\mathrm{M}=$ Micro-crack state

$\mathrm{D}=$ Macro-crack state (reflecting mainly radial morphology)

$\mathrm{C}=$ Macro-crack state (reflecting mainly circumferential morphology)

$\mathrm{L}=$ Leak state

$\mathrm{R}=$ Ruptured state

These states, along with the inter-state transitions, are now defined: 


\subsection{Initial State S}

The initial state describes an ASME Class 1 Alloy 182/82 weld in the pressurizer surge line at the vessel nozzle safe end joining reactor coolant piping with the pressurizer. The installation, fabrication, and repairs undertaken on this weld, as well as the operating environmental factors influence its susceptibility to SCC crack initiation. While the initial state may represent some distribution of microphysical flaws at which micro-cracks may ultimately nucleate, there are assumed to be no detectable anomalies or cracks while in state $\mathrm{S}$.

\subsection{Micro-Crack State M}

State $M$ is one in which an SCC micro-crack has initiated at some given location on the inside surface of the pipe weld. The red arrow to $M$ in Figure 3-1 represents a transition from the initial state to the micro-crack state (the physics of which is described in Appendix 1). A micro-crack is assumed to be undetectable by conventional NDE techniques. Once the crack has grown to NDE-detectable depth, then the component has transitioned to a macro-crack state (D or C). The blue arrow from state $\mathrm{M}$ to $\mathrm{S}$ reflects the fact that emerging prognostic monitoring techniques could in principle allow a micro-crack to be detected. By including this repair transition in the model, then R7 may potentially provide insight on the efficacy and risk-impact of various prognostic monitoring technologies.

Micro-crack development is influenced by grain size, structure, orientation, and stress intensity factors. The assumption is that the initial distribution of flaws along with the geometry of the physical stressors determines whether the micro-crack state ultimately transitions to the radial macro-crack state (D) or the circumferential macro-crack state (C).

\subsection{Radial Macro-Crack State D}

This state reflects one in which a macro-crack of primarily radial orientation (see Figure 2-2A) has formed due to crack growth and is potentially detectable by conventional NDE. A crack depth threshold, $a_{D}$, is established to define when state D has been entered (see Appendix 1).

Making distinction between radial and circumferential macro-cracks is important for several reasons. First, crack growth rate is sensitive to the crack morphology. The stress intensity factor at the crack tip, which contributes to determining growth rate, is dependent on the crack aspect ratio. For the purposes of the current model, the aspect ratio (of crack depth to length) for a radial crack is assumed to be 1 , and for a circumferential crack, 0.1. Based on crack growth correlations from the pc-PRAISE [9] model, crack growth rate is considerably greater for circumferential cracks. (Details of this analysis are presented in Appendix 2.) Second, predisposition to pipe rupture (before leak) and the impact of crack size on pipe strength are sensitive to the crack morphology [8]. That is, a circumferential crack is more likely to transition directly to a rupture (without intermediate leak) than a radial crack. 
As the crack depth grows radially through the weld, leakage occurs when the macro-crack reaches the outside wall. The possibility of a repair transition before a through-wall crack occurs is reflected in the blue arrow from $D$ to $S$. The bases for quantification of the repair transitions are conventional and based on inspection rates and detection probabilities (see Section 4).

Due to the unavailability of relevant physical models, the basis for assessing the split probability between $M \rightarrow D$ versus $M \rightarrow C$ transitions is empirical and based on the relative numbers of radial versus circumferential macro-cracks represented in service data (Appendix 1).

\subsection{Circumferential Macro-Crack State C}

This state reflects one in which a macro-crack of primarily circumferential orientation (see Figure $2-2 B$ ) has formed due to crack growth and is potentially detectable by conventional NDE. A crack depth threshold, $a_{c}$, is established to define when state $C$ has been entered (see Appendix 1).

The rationale for distinguishing between crack morphologies was described in the previous subsection. For the purposes of the current analyses, the aspect ratio (of crack depth to length) for a circumferential crack is assumed to be 0.1 . Based on crack growth correlations in the software pc-PRAISE [9], crack growth rate is considerably greater for circumferential cracks. (Details of this analysis are presented in Appendix 2.)

The circumferential crack grows more rapidly around the inside diameter than through the wall of the weld. However, once the crack depth reaches the outside wall of the weld, a rupture is assumed to occur. A repair transition before a through-wall crack occurs is reflected by the blue arrow from $\mathrm{C}$ to $\mathrm{S}$. The bases for quantification of the repair transition probabilities are conventional and are based on inspection rates and detection probabilities (see Section 4).

\subsection{Leak State L}

Transition to this state occurs when the radial macro-crack depth becomes equal to the pipe wall thickness. For the component under analysis, the crack depth that results in a leak is 3.8E$2 \mathrm{~m}$.

The possibility of leak repair is represented by the blue arrow from $L$ to $S$. Quantification of this transition probability is based on the frequency of leak tests and on leak detection probabilities (see Section 4).

\subsection{Rupture State R}

Pipe rupture is assumed to occur when the crack size has grown to dimensions at which the weld has insufficient strength to retain the system pressure. The failure pressure model is described in detail in Section 4. R7 dictates the physical environment in which the system 
pressure (either in normal operations or during a transient) is assessed, and then compared to the weld failure pressure to determine whether a transition to the rupture state occurs.

In general, where the multistate model indicates multiple arrows emerging from a single state, (such as a repair transition versus continued degradation), then the cumulative damage model (described in Section 4) provides the basis for determining which of the transitions occurs under a given set of physical circumstances. 


\section{The Cumulative Degradation (Heartbeat) Framework}

For compatibility with the R7 modeling environment, the passives multi-state reliability models will need to be cast in a cumulative damage framework. The framework has been outlined by Idaho National Laboratory [10]. In this section, salient aspects of the framework are briefly summarized and the SCC passives reliability model is then expressed and quantified in that framework. While the passives model must ultimately be executed in an R7 environment, some preliminary results based on implementation of the model in isolation have been generated to exemplify the structure of the outputs.

\subsection{Framework Description}

In the cumulative degradation framework, a component is considered to fail once a certain amount of damage has accumulated. Consider a component with a time-dependent reliability function $\mathrm{R}$ of the Weibull form:

$$
R(t, x, y)=\exp \left[-(t / x)^{y}\right]
$$

where $t$ is time, $\mathrm{x}$ is the scale factor and $\mathrm{y}$ is the shape factor. $\mathrm{R}$ is the probability of component survival by time $t$. In the cumulative damage model, the parameter $\mathrm{x}$ is assumed to be a function of the physical environment in which the component is operating; that is, it can be equated to some function of physical parameters. If $x$ is viewed as a characteristic survival time, then $x$ would be expected to be smaller the harsher the physical environment. If $x$ can be expressed as a function of the physical parameters that govern the cumulative damage to the component, then implications for the expected component lifetime can be related to changes in physical environment.

In the R7 modeling paradigm, the notion is that a Monte Carlo sample of key event times is generated at the outset of an analysis, and the deterministic R7 model is then subsequently run for each sample member. In the context of the treatment of a single component, this would mean that Equation 4.1 is the basis for generating a sample of failure times, t. (Each sample member would in fact reflect a single realization of every parameter that is treated stochastically in the R7 analysis.) However, because physical conditions predicted by R7 in any single sample member would be expected to evolve, then the value of $x$ in Equation 4.1 that formed the original basis for the failure time sample would change. The so-called heartbeat principle allows adjustment of the component failure time in light of the evolving physical environment without the need to resample. Specifically, if (in a given sample member) in time interval $\Delta t_{i}$ the value of the physics-based scale parameter becomes $x_{i}$, then the accumulated "damage" in that interval is expressed as

$$
\Delta t_{i} \cdot x / x_{i}
$$


where $x$ was the original value of the scale parameter. If in a given sample member $t_{s}$ was the originally sampled failure time, then the failure time that reflects the evolving conditions predicted by $\mathrm{R} 7$ is $\mathrm{t}_{\mathrm{s}}$, where

$$
\mathrm{t}_{\mathrm{s}}=\Delta \mathrm{t}_{\mathrm{i}}
$$

and $n$ satisfies

$$
\mathrm{t}_{\mathrm{s}}=\Delta \mathrm{t}_{\mathrm{i}} \mathrm{x} / \mathrm{x}_{\mathrm{i}}
$$

In the context of the SCC passives model, the heartbeat principle is generalized to apply not just to component failure times, but to general state transition times.

While the Weibull formulation of state transition time probabilities is not a necessary condition for implementation of the heartbeat principle, Weibull models form the basis for the current physics-based SCC failure model.

Figure 4-1 shows the SCC multi-state failure model in the cumulative damage (heartbeat) implementation developed for R7 integration. The state transitions represented by red arrows reflect progressive component degradations. The blue arrows reflect state transitions associated with interventions and component restoration to the initial success state. The green arrows represent transitions to the rupture state which are treated in a qualitatively distinct way from other transitions, to be outlined later in this section.

For all the transitions (other than rupture), the transition times are sampled from Weibull distributions of the form captured in Equation 4.1.

Specifically (with reference to Figure 4-1 and Equation 4.1):

- $S$ to $M$ : Here $x$ is a function of physical parameters that include crack activation energy, operating temperature, and operating stresses. $y$ is an empirical value.

- $\quad M$ to $C, M$ to $D$, and $D$ to $L$ : Here $x$ is a function of physical parameters such as stress intensity factors, operating temperature, operating pressure, and crack growth activation energy. The value of $y$ is dictated by physical conditions.

For these transitions, the heartbeat principle is applied by, in any one Monte Carlo sample member, adjusting the transition time based on the impact of the evolving physical conditions on the scale parameter, $\mathrm{x}$ (per Equation 4.3).

- $\quad$ M to S, D to S, and C to S: These are the intervention and repair transitions which, per convention in reliability analyses, are assumed to be Poisson processes - the special case of the Weibull process in which $y=1$. The value of $x$ is based on inspection strategies and human reliability estimates. Here, we assume that the heartbeat principle 
of transition time adjustment would not be relevant since the transition rates are not driven by $\mathrm{R} 7$ physics.

- C to R, D to R, L to R: The time of transition to rupture is not sampled a priori like the other transition times. Instead, a rupture is assumed to occur when the component is in a vulnerable state $(C, D$, or $L)$ and $R 7$ then predicts a pressure transient that exceeds the failure pressure of the degraded component. Therefore, the passives model estimates the failure pressure of the component as a function of the time after the component entered a vulnerable state. If at some time in the simulation R7 predicts an operating pressure that exceeds the failure pressure, then a rupture is assumed to occur.

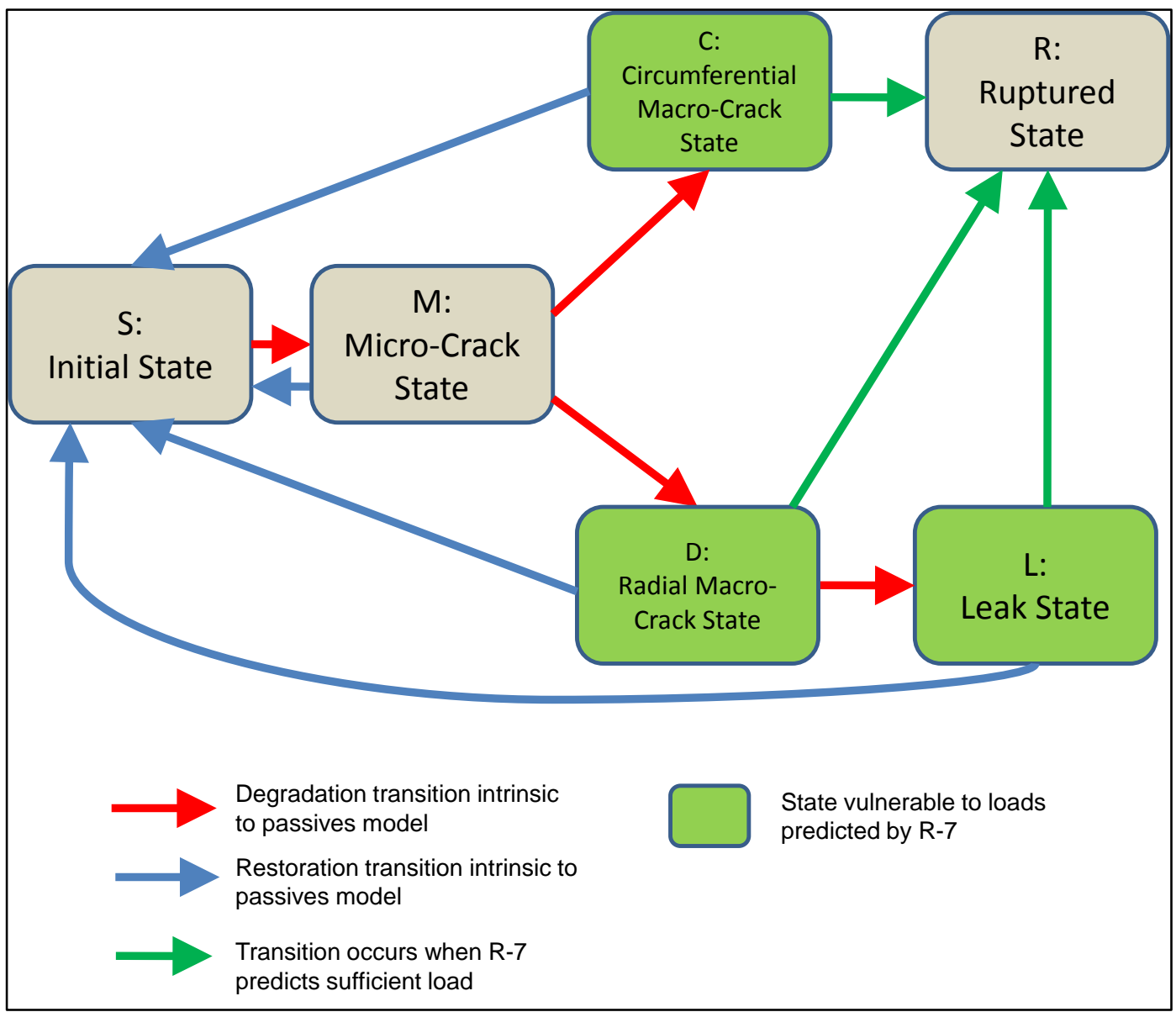

Figure 4-1 Multi-State Model: Cumulative Damage Implementation

Note that in any one history (i.e., R7 sample member), the component will experience a unique sequence of state transitions. It is assumed that the $\mathrm{R} 7$ environment will track the sampled state transition times and their adjustments via the heartbeat principle to construct that unique history. 
Figure 4-2 helps demonstrate the principle for constructing a unique history based on one initial sample member of transition times; that is, prior to heartbeat-based transition time adjustments. Construction of a unique a priori sequence for a given sample member involves comparison of the transition times it contains. That is, if there are multiple competing states to which a component can transition from a given state, then it is the state with the shortest transition time (for that sample member) to which the component is assumed to transition. For example, the sample member may contain, for the microcrack state $M$, a transition time to repair that is shorter than the transition time to macrocrack formation. In this case, the $\mathrm{M} \rightarrow \mathrm{S}$ transition occurs. Figure 4-2 is an event tree that selects the unique state history for a given sample member of transition times. In this simplified tree, the history is cut off after 80 years and, if a component is repaired, the history is terminated.

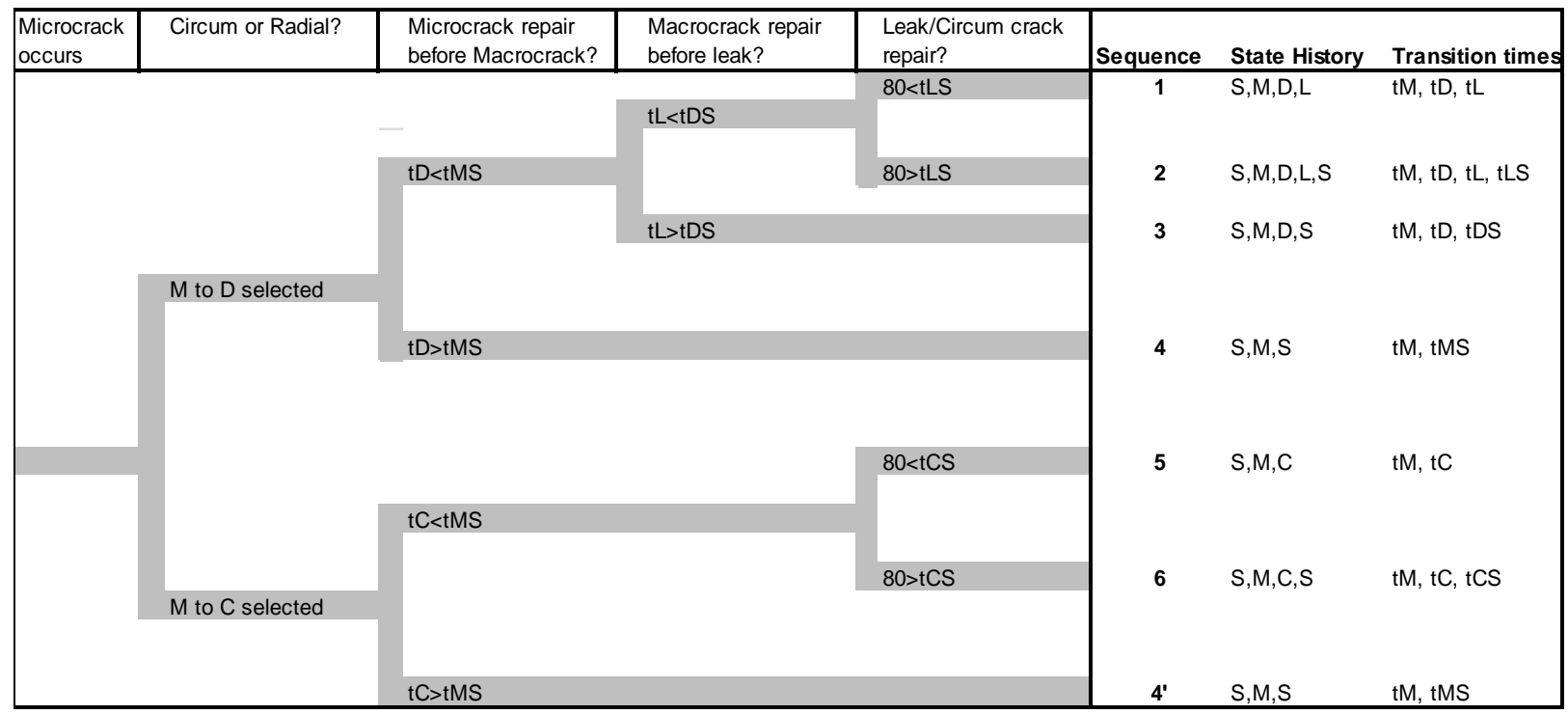

\begin{tabular}{|l|l|}
\hline Sequence & Description \\
\hline 1 & Micro, Radial, Leak \\
\hline 2 & Micro, Radial, Leak, Repair \\
\hline 3 & Micro, Radial, Repair \\
\hline 4 and 4' & Micro, Repair \\
\hline 5 & Micro, Circum \\
\hline 6 & Micro, Circum, Repair \\
\hline
\end{tabular}

Figure 4-2 Degradation Sequence Event Tree

In Appendix 1 the physics models and their quantifications for the current baseline analysis are described. The rest of this section describes the bases for construction of the state transition cumulative damage models from those physics models, along with supplementary analyses required to implement the multi-state model. 


\subsection{Initial to Micro-crack Transition: S to M}

The physics-based model of transition from the initial state $S$ to micro-crack state $M$ is stochastic in nature. Since the physics model is already been cast in a Weibull form and is compatible with the cumulative damage framework, no further restructuring of the model is required. The model is described in Section A1.1 of Appendix 1, and the cumulative damage Weibull formulation is defined in Equations A1.1 and A1.3.

\subsection{Micro-crack to Radial or Circumferential Macro-crack Transition: M to D or C}

The macro-crack state is reached when the crack depth reaches the threshold of $2.0 \mathrm{E}-04 \mathrm{~m}-\mathrm{a}$ depth consistent with NDE capability. Expression 4.4 represents the equation for crack depth growth rate discussed in Appendix 1:

$\mathrm{da} / \mathrm{dt}=\mathrm{fn}$ (stress intensity, temperature, activation energy, fitting factors).

Implementation of this expression requires the use of models that estimate the stress intensity factor, K, as a function crack dimensions and other physical parameters. For our analyses, the pc-PRAISE [9] code was used. Since repeated use of pc-PRAISE will be impractical in an R7 setting, analytical simplifications have been developed that (1) allow crack growth rates to be rapidly estimated and (2) relate crack growth rates to the parameterization of the cumulative degradation model.

Based on a series of analysis case runs, power law relationships between crack depth and time from crack initiation were established for various sets of physical conditions:

$a=\alpha t^{\theta}$.

The objective was to establish the values of $\alpha$ and $\theta$ for a range of the R7-provided physical variables (which we refer to as the physical parameters exogenous to the passives model - in this case, operating pressure and temperature). More precisely, we wish to capture the aleatory variability in crack growth rate (modeled as aleatory variability in $\alpha$ and $\theta$ associated with factors such as metallurgical variability) for various combinations of the exogenous parameters. As will be shown in the case analyses, the empirical result is that $\alpha$ captures the variability in growth rates while the exponent remains relatively constant for a given crack morphology (radial versus circumferential).

Before outlining the details of the model fitting process, the general cumulative damage methodology for the macro-crack transitions is described.

Starting with Equation 4.5, the probability, $F(t)$, of a transition to a macrocrack by time $t$ from microcrack initiation is

$$
F(t)=\operatorname{Prob}\left(a^{\prime}<\alpha t^{\theta}\right)=\operatorname{Prob}\left(\alpha>a^{\prime} / t^{\theta}\right)={ }_{a^{\prime} / t \theta} \int^{\infty} \Pi(\alpha) d \alpha=1-C\left(a^{\prime} / t^{\theta}\right)
$$


Here, $a^{\prime}$ is the crack depth that defines a macro-crack $\left(a_{D}, a_{C}: 2 E-4 m\right.$ for both radial and circumferential cracks). $\Pi(\alpha)$ is the aleatory probability density over $\alpha$ and $\mathrm{C}(\alpha)$ is the cumulative probability function.

We associate the aleatory variability in $\alpha$ with variability in physical parameters that are endogenous to the passives model. Inputs necessary for the cumulative damage model are the Weibull distribution scale and shape parameters. If $F(t)$ is of a Weibull form, this is sufficient to support the cumulative damage model; that is

$\mathrm{F}(\mathrm{t})=1-\exp \left[-\left(t / \eta_{G}\right) r\right]$

where $\eta_{G}$ is the scale parameter and $\gamma$ the shape parameter. This can be achieved if we assume that the distribution over $\alpha$ is of an inverse Weibull form (see Figure 4-3), i.e.,

where $\alpha_{0}$ is a scale parameter and $\varphi$ a shape parameter.

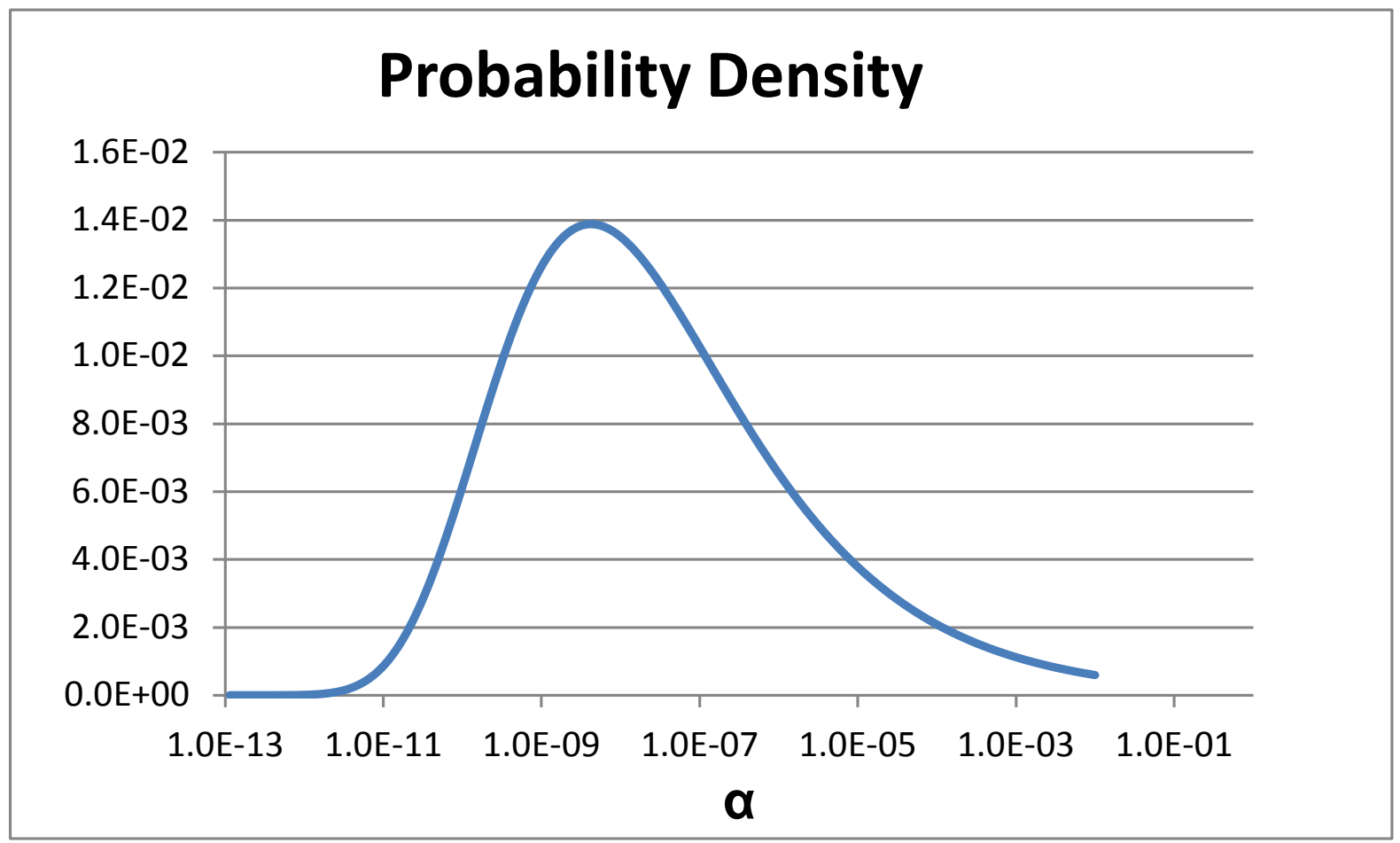

Figure 4-3: Example Form of an Inverse Weibull Distribution.

In this case, using (4.6) and (4.8), we have that

$\mathrm{F}(\mathrm{t})=1-\exp \left[-\left(\alpha_{0} t^{\theta} / \mathrm{a}^{\prime}\right)^{\varphi}\right]$ 
Then Equation 4.9 can be identified with Equation 4.7, where the Weibull parameters are given by

$\eta_{G}=\left(a^{\prime} / \alpha_{0}\right)^{1 / \theta}$

and

$\gamma=\theta \varphi$

$\varphi$ and $\alpha_{0}$ now need to be set. In general, these parameters are a function of the exogenous physical conditions. Those exogenous conditions (per the crack growth model) are operating temperature, $(T)$, and operating pressure, $(P)$. So, for a given combination of $P$ and $T$, we associate a stochastic range over $\alpha$ with the aleatory variability in the endogenous physical parameters of the model. If we establish a range over $\alpha$ for a given $P, T$ combination and interpret it as the 5th to 95th interval, then we can assess $\varphi$ and $\alpha_{0}$ as

$\varphi=4.06738 / \ln \left(\alpha_{95} / \alpha_{5}\right)$.

and

$\alpha_{0}=\exp \left(0.2698 \ln \alpha_{95}+0.7302 \ln \alpha_{5}\right)$.

Based on consideration of the uncertainties and output sensitivities associated with each of the input parameters to Equation 4.4 (see Appendix 1, Equation A1.4), it is the crack growth amplitude fitting constant $\varepsilon$ that is the principal driver of the aleatory variability associated with the endogenous parameters.

pc-PRAISE runs were conducted for the cases shown in Table 4-1. Based on fits to Equation 4.5 , the values of $\alpha_{95}, \alpha_{5}$ and $\theta$ were estimated for each case. The value of $\alpha_{95}$ is based on use of the upper value of the crack growth amplitude parameter $\varepsilon$ (see Appendix 1, Section A1.2), and $\alpha_{5}$ on the lower value of $\varepsilon$ ). Equations 4.10 to 4.13 then provide the basis for estimating the Weibull parameters. These are also shown in Table 4-1. 
Physics-Based SCC Reliability Model in a Cumulative Damage Framework

Table 4-1 Cumulative Damage Weibull Parameters for Macro-Crack Transitions

\begin{tabular}{|c|c|c|c|c|c|c|c|c|c|}
\hline \multirow[b]{2}{*}{ Crack Type } & \multicolumn{2}{|c|}{ Exogeneous Physics } & \multicolumn{2}{|c|}{ Crack Growth Fit } & \multirow[b]{2}{*}{$\theta$} & \multicolumn{2}{|c|}{ Inverse Weibull Fit } & \multicolumn{2}{|c|}{ Weibull Damage } \\
\hline & $\mathrm{T}_{\mathrm{op}}\left({ }^{0} \mathrm{~K}\right)$ & $P_{\text {op }}$ (Mpa) & $\alpha_{95}$ & $\alpha_{5}$ & & $\alpha_{0}$ & $\varphi$ & $\eta_{G}$ (yrs) & $Y$ \\
\hline \multirow[t]{11}{*}{ Radial } & 400 & 15.1 & $2.0 \mathrm{E}-67$ & $1.0 \mathrm{E}-72$ & 6.1871 & 2.7E-71 & $3.3 \mathrm{E}-01$ & $6.4 \mathrm{E}+10$ & 2.06 \\
\hline & 450 & 15.1 & $1.0 \mathrm{E}-48$ & $9.0 \mathrm{E}-54$ & 6.1851 & $2.1 \mathrm{E}-52$ & $3.5 \mathrm{E}-01$ & $5.7 \mathrm{E}+07$ & 2.17 \\
\hline & 500 & 15.1 & $1.0 \mathrm{E}-33$ & $1.0 \mathrm{E}-38$ & 6.1866 & $2.2 \mathrm{E}-37$ & $3.5 \mathrm{E}-01$ & $2.1 \mathrm{E}+05$ & 2.19 \\
\hline & 550 & 15.1 & 3.0E-21 & $2.0 \mathrm{E}-26$ & 6.1865 & $5.0 \mathrm{E}-25$ & $3.4 \mathrm{E}-01$ & $2.1 \mathrm{E}+03$ & 2.11 \\
\hline & 600 & 15.1 & $5.0 \mathrm{E}-11$ & $4.0 \mathrm{E}-16$ & 6.1864 & $9.5 \mathrm{E}-15$ & $3.5 \mathrm{E}-01$ & 4.7E+01 & 2.14 \\
\hline & 650 & 15.1 & 2.7E-02 & 2.0E-07 & 6.1868 & $4.8 \mathrm{E}-06$ & $3.4 \mathrm{E}-01$ & $1.8 \mathrm{E}+00$ & 2.13 \\
\hline & 525 & 10.0 & $6.0 \mathrm{E}-29$ & $5.0 \mathrm{E}-34$ & 6.1869 & $1.2 \mathrm{E}-32$ & $3.5 \mathrm{E}-01$ & 3.7E+04 & 2.15 \\
\hline & 525 & 12.0 & $4.0 \mathrm{E}-28$ & $3.0 \mathrm{E}-33$ & 6.1869 & $7.2 E-32$ & $3.4 \mathrm{E}-01$ & $2.7 \mathrm{E}+04$ & 2.13 \\
\hline & 525 & 14.0 & 2.0E-27 & $1.0 \mathrm{E}-32$ & 6.1865 & 2.7E-31 & 3.3E-01 & $2.2 \mathrm{E}+04$ & 2.06 \\
\hline & 525 & 16.0 & 7.0E-27 & $5.0 \mathrm{E}-32$ & 6.1866 & $1.2 \mathrm{E}-30$ & $3.4 \mathrm{E}-01$ & 1.7E+04 & 2.12 \\
\hline & 525 & 18.0 & $2.0 \mathrm{E}-26$ & $2.0 \mathrm{E}-31$ & 6.1867 & $4.5 \mathrm{E}-30$ & $3.5 \mathrm{E}-01$ & $1.4 \mathrm{E}+04$ & 2.19 \\
\hline \multirow[t]{11}{*}{ Circumferential } & 400 & 15.1 & $3.0 \mathrm{E}-87$ & $4.0 \mathrm{E}-94$ & 8.3084 & $2.9 \mathrm{E}-92$ & $2.6 \mathrm{E}-01$ & $3.7 E+10$ & 2.13 \\
\hline & 450 & 15.1 & 7.0E-62 & $9.0 \mathrm{E}-69$ & 8.3097 & $6.5 E-67$ & 2.6E-01 & $3.3 \mathrm{E}+07$ & 2.13 \\
\hline & 500 & 15.1 & $1.0 \mathrm{E}-41$ & $2.0 \mathrm{E}-48$ & 8.3081 & $1.3 \mathrm{E}-46$ & 2.6E-01 & $1.2 \mathrm{E}+05$ & 2.19 \\
\hline & 550 & 15.1 & 4.0E-25 & $6.0 \mathrm{E}-32$ & 8.3074 & $4.2 \mathrm{E}-30$ & 2.6E-01 & $1.2 \mathrm{E}+03$ & 2.15 \\
\hline & 600 & 15.1 & 3.0E-11 & 4.0E-18 & 8.3069 & $2.9 \mathrm{E}-16$ & $2.6 \mathrm{E}-01$ & 2.7E+01 & 2.13 \\
\hline & 650 & 15.1 & $1.3 \mathrm{E}+01$ & $2.0 \mathrm{E}-06$ & 8.3079 & $1.4 \mathrm{E}-04$ & 2.6E-01 & $1.0 \mathrm{E}+00$ & 2.15 \\
\hline & 525 & 10.0 & $2.0 \mathrm{E}-35$ & $3.0 \mathrm{E}-42$ & 8.3071 & $2.1 \mathrm{E}-40$ & 2.6E-01 & $2.1 \mathrm{E}+04$ & 2.15 \\
\hline & 525 & 12.0 & 3.0E-34 & $4.0 \mathrm{E}-41$ & 8.3075 & $2.9 \mathrm{E}-39$ & 2.6E-01 & $1.6 \mathrm{E}+04$ & 2.13 \\
\hline & 525 & 14.0 & $2.0 \mathrm{E}-33$ & $3.0 \mathrm{E}-40$ & 8.3070 & $2.1 \mathrm{E}-38$ & 2.6E-01 & $1.2 \mathrm{E}+04$ & 2.15 \\
\hline & 525 & 16.0 & $1.0 \mathrm{E}-32$ & $2.0 \mathrm{E}-39$ & 8.3079 & $1.3 \mathrm{E}-37$ & 2.6E-01 & $9.9 \mathrm{E}+03$ & 2.19 \\
\hline & 525 & 18.0 & $6.0 \mathrm{E}-32$ & 8.0E-39 & 8.3071 & $5.7 E-37$ & $2.6 \mathrm{E}-01$ & $8.3 \mathrm{E}+03$ & 2.13 \\
\hline
\end{tabular}

As previously noted, we see that for a given crack morphology, the crack growth exponent $\theta$ is about constant. The Weibull shape parameter $\gamma$ is constant across exogenous parameter values (and between crack morphologies). This is desirable since a physics dependence in the Weibull shape parameter may be problematic in implementation of the heartbeat principle.

Through regression, the data in Table 4-1 were used to fit a simple analytical expression relating the Weibull parameters to the exogenous physics parameters. For the transition to radial macrocrack, the resultant expression is:

$\ln \eta_{G}=25,248 T^{-1}-0.12 P-36.4$

and $\gamma=2.1$

where $\mathrm{T}(\mathrm{K})$ and $\mathrm{P}(\mathrm{MPa})$ are the operating temperature and pressure, respectively, and the scale parameter $\eta_{\mathrm{G}}$ is measured in years.

For the transition to circumferential macrocrack, we have that 
$\ln \eta_{G}=25,262 T^{-1}-0.12 P-37.0$

and $\gamma=2.1$.

These correlations have been established over the ranges

- $\mathrm{T}=400-650 \mathrm{~K}$

- $\mathrm{P}=10-18 \mathrm{MPa}$.

It can be seen that operating temperature $\mathrm{T}$ is the principal driver of the Weibull scale parameter. At $\mathrm{P}=15.1 \mathrm{MPa}$ and $\mathrm{T}=525 \mathrm{~K}, \mathrm{\eta}_{\mathrm{G}}$ is equal to 19,525 and 11,005 years for radial and circumferential crack transitions, respectively.

\subsection{Radial Macro-Crack to Leak Transition: D to L}

There are some dependencies to be accounted for in the leak transition. Once a transition time for radial macro-crack has been sampled, this has in effect set the crack depth time dependence in each sample member. Since leak is the result of continued crack growth in that sample member, it should be based on the same crack growth rate assumptions.

Note that since a circumferential crack occurs exclusively from a radial crack in a given sample member, there should be no constraints on correlations in crack growth rate parameters between circumferential and radial morphologies. It is possible that a single realization could have both radial and circumferential growth if there's a repair in-between, but the repair itself possibly eliminates the basis for correlations. Our model has confined attention to the dependence between the radial crack and leak transitions.

Assume the radial crack transition time (i.e., the residence time in $M$ ) is sampled as $t_{D}$ in a given sample member. From Equation 4.5, the effective value of $\alpha$ corresponding to this transition time is

$$
a_{D}=a_{D} / t_{D}{ }^{\theta} .
$$

Assuming no detection has occurred, the macro-crack progresses to a leak state based on the behavior of Equation 4.5. Based on the radial crack transition time $t_{D}$ we can now determine the leak transition time $t_{L}$, where $t_{L}$ is the time from radial macro-crack formation. If $a_{L}$ is the crack depth threshold for leak (i.e., a through-wall crack, $a_{\llcorner}=3.8 E-2 m$ ), then

$$
a_{L}=a_{D}\left(t_{D}+t_{L}\right)^{\theta} .
$$

Therefore,

$$
t_{L}=\left[\left(a_{L} / a_{D}\right)^{1 / \theta}-1\right] t_{D}
$$


Inserting the crack depth threshold values, we have that $t_{L}=1.34 t_{D}$.

\subsection{Transitions to Rupture: $\mathbf{R}$}

Transition to rupture is assumed to occur if the component is in a vulnerable state and R7 then predicts an operating pressure that exceeds the component failure pressure. While, in principle, a severe enough transient could cause transition to rupture from any of the other states, the failure pressure estimates provided by the rupture model (to be described) lead to identification of the macrocrack (C and $D)$ and the leak state $(L)$ as the credible vulnerable states.

The R7-compatible model for rupture involves estimation of the component failure pressure as a function of time after entering a vulnerable state. At any one time, the failure pressure can then be compared to the operating pressure predicted in a given $\mathrm{R} 7$ simulation to determine if rupture occurs.

A modified version of the Battelle model [8] of pipe performance is adopted (where alternative models could in future be the bases for epistemic uncertainty analyses). As described in Appendix 1 , the rupture pressure, $\mathrm{P}_{\mathrm{f}}$, is estimated as

where

$h$ is the pipe wall thickness $(0.038 \mathrm{~m}), \mathrm{H}$ is the pipe diameter $(0.3048 \mathrm{~m}), \sigma_{F}$ is the material flow stress (333 MPa), $a$ is the crack depth and $b$ is the crack length.

Figure 4-4 shows the component rupture failure pressure as a function of crack depth for both the radial macrocrack state (D) and the circumferential macrocrack state (C). 


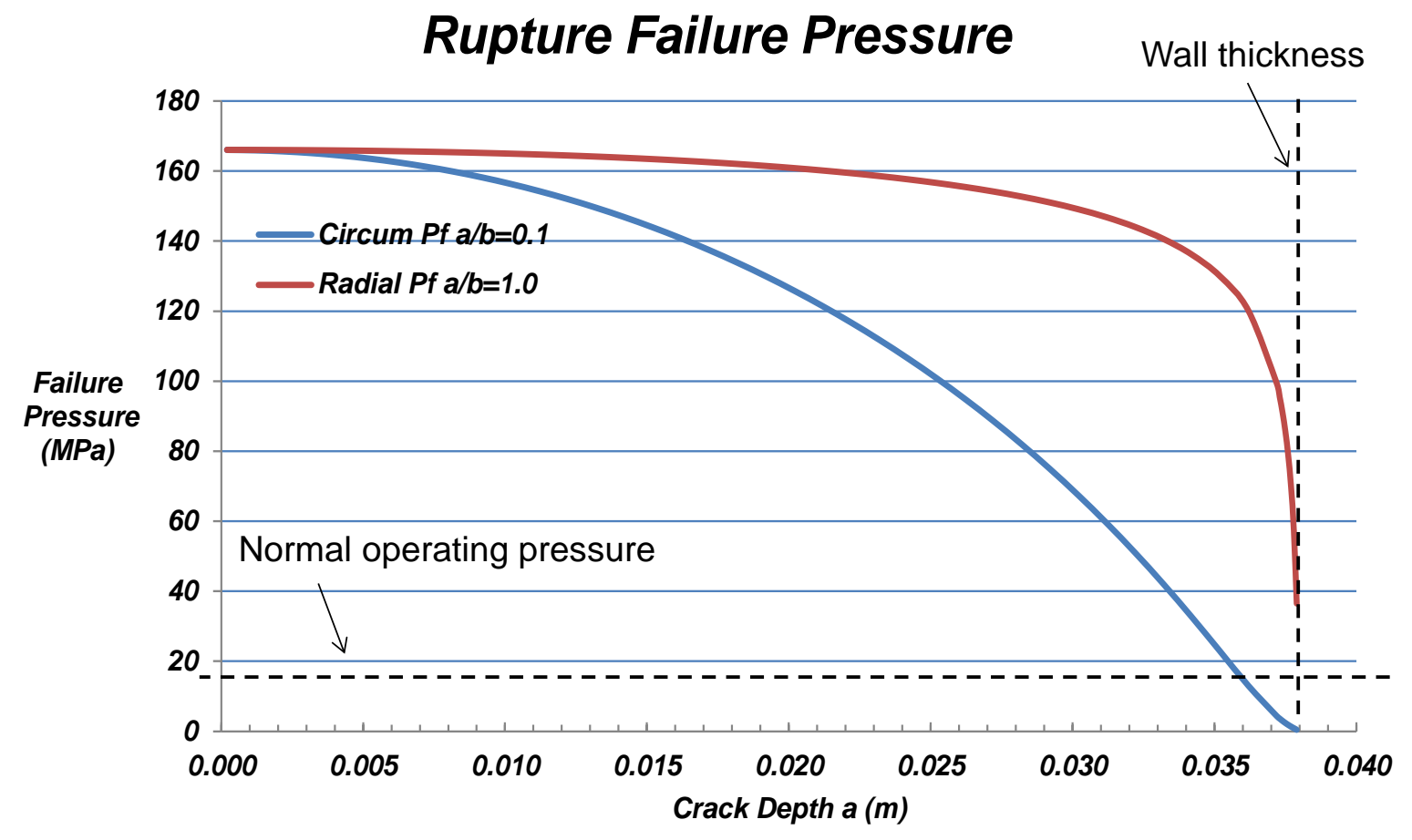

Figure 4-4: Rupture Pressure

First consider state $\mathrm{C}$. Once the transition time to circumferential macrocrack (from microcrack initiation) has been sampled as $t_{C}$, this has implications for the value $\alpha$ in that sample member. Using Equation 4.5, we see that in that sample member, the value $\alpha$ is assessed to be

$a_{c}=a_{c} / t_{c}{ }^{\theta}$

If a transient occurs while the component is still in state $C$, then the size of the crack (per Equation 4.17) at the time of the transient will dictate whether or not the component ruptures. At time $y$ after the initiation of a circumferential macrocrack, the crack length $a$ is given by

$a=a_{c}\left(t_{c}+y\right)^{\theta}$

and using Equation 4.19 for $\alpha_{C}$, we have that

$\mathrm{a}=\mathrm{a}_{\mathrm{c}}\left(\mathrm{t}_{\mathrm{c}}+\mathrm{y}\right)^{\theta} / \mathrm{t}_{\mathrm{c}}{ }^{\theta}$

This estimate of crack depth can then be inserted into Equation 4.17 to assess the component rupture pressure at the time of the transient. For the circumferential macrocrack, the crack aspect ratio is set at $0.1(b=10 a)$. The failure pressure assessed by Equation 4.17 can be compared to the magnitude of the transient predicted by $\mathrm{R} 7$ to determine whether rupture occurs in that Monte Carlo sample member. 
For a component in the $\mathrm{D}$ or $\mathrm{L}$ state at the time of the crack, the treatment is similar:

$a=a_{D}\left(t_{D}+y\right)^{\theta} / t_{D}{ }^{\theta}$

For the radial crack, the crack aspect ratio is set to $1(b=a)$. Note, we have assumed previously that the leak state $L$ occurs once the radial crack depth reaches $a_{L}$, which was equated to the wall thickness. However, Equation 4.17 then predicts that rupture would always occur before leak; that is, it occurs once the crack depth is sufficient to result in rupture at normal operating pressure. To account for leak before break, we adjust Equation 4.17 such that when in state $D$ or $\mathrm{L}$, the rupture pressure is set no lower than $20 \mathrm{MPa}$ (5 MPa above operating pressure). This has the effect of requiring transient conditions to produce a rupture. In contrast, circumferential cracks are allowed to transition directly to rupture without an intermediate leak, and no rupture pressure threshold is applied.

\subsection{Repair transitions: $M$ to $S, D$ to $S, C$ to $S, L$ to $S$}

We assume a Poisson distribution of repairs based on constant transition rates. That is

where $\lambda$ is the constant rate of crack discovery and successful repair and $F(t)$ is the probability of repair by time $t$ after the degraded state is entered. This formulation applies to four types of transitions:

Microcrack to initial: $\lambda_{\mathrm{M}}$,

Radial macrocrack to initial: $\lambda_{\mathrm{D}}$,

Circumferential macrocrack to initial: $\lambda_{\mathrm{C}}$,

Leak to initial: $\lambda_{\mathrm{L}}$.

This Poisson model is a special case of Weibull, although we'll assume there's no basis for adjusting these rates in light of changes in physical conditions, and therefore the heartbeat rescaling won't apply to repair transitions.

Quantification of the transition rates is based on the Fleming Markov model of pipe failures [11] which considers weld inspection rates and sampling strategies, leak test rates, flaw/leak discovery probabilities, and successful repair probabilities. The Fleming model does not address microcrack states since the crack repair rates are based on conventional NDE inspections and leak tests. A technology for microcrack discovery is not yet deployed commercially, but in anticipation of prognostic monitoring techniques, microcrack repairs are included in our model. A nominal repair rate for microcracks is used for now. For repair transitions, the rates currently used are:

$$
\lambda_{M}=1 \mathrm{E}-3 / \mathrm{yr}
$$


Physics-Based SCC Reliability Model in a Cumulative Damage Framework

$$
\begin{aligned}
& \lambda_{\mathrm{D}}=2 \mathrm{E}-2 / \mathrm{yr} \\
& \lambda_{\mathrm{C}}=2 \mathrm{E}-2 / \mathrm{yr} \\
& \lambda_{\mathrm{L}}=8 \mathrm{E}-1 / \mathrm{yr} .
\end{aligned}
$$




\section{Model Implementation}

The intent is that the cumulative damage model described here will be implemented in a full R7 environment. However, to provide a sense of the structure of the outputs from the multi-state model, results of some baseline analyses are presented in this section. By baseline is meant that for a single set of physical model quantifications, a Monte Carlo sample of state transition histories is generated. In a full analysis setting, the state transition histories and their timings would be adjusted in accordance with heartbeat principles to reflect the evolving physical environment predicted by R7.

Note that since the characteristic Weibull transition times (scale factors) for crack initiation and macro-crack formation are each of the order of $10^{4}$ years, a state transition for any single component within a plant lifetime of, say, 80 years is very unlikely. Therefore, for the purposes of conveying the form of the model results in this section, the Weibull eta factors for crack initiation and macro-crack formation have each been arbitrarily decreased to $0.3 \%$ of the baseline values estimated in this report. Also, to allow more output features to be displayed, the leak repair rate has been decreased by an order of magnitude.

Table 5-1 shows a limited number of Monte Carlo sample members and the associated sequences of transitions. The table includes the rupture vulnerability window, which is the time frame over which the component resides in a macrocrack or leak state (see Figure 4-1). In this simplified analysis, we assume that once (if) the component is restored to the Initial state, then the transition history is terminated (see Figure 4-2). More generally, we would allow the component to re-initiate degradation after a repair has occurred.

Table 5-1 Sample of State Transition Histories

\begin{tabular}{|c|c|c|c|c|}
\hline \multirow[b]{2}{*}{ Sample Member } & \multirow[b]{2}{*}{ Sequence } & 30 -year cutoff & \multicolumn{2}{|c|}{ Rupture Vulnerability Window (Years) } \\
\hline & & Event Times (years) & \begin{tabular}{|c} 
Rupture Vulnerabili \\
time start
\end{tabular} & $\begin{array}{l}\text { (Years) } \\
\text { time end }\end{array}$ \\
\hline & 1 Microcrack, Circum Crack, & $40.5,51.2$ & 51.2 & 80.0 \\
\hline & 2 Microcrack,Radial Crack, & $37.4,64.8$ & 64.8 & 80.0 \\
\hline & 3 Microcrack,Radial Crack,Repair, & $25.7,56,67.3$ & 56.0 & 67.3 \\
\hline & 4 Microcrack,Radial Crack, & $17,57.3$ & 57.3 & 80.0 \\
\hline & 5 Microcrack, Radial Crack, Repair, & $23,44.1,64.2$ & 44.1 & 64.2 \\
\hline & 6 Microcrack,Radial Crack, & $35.2,75$ & 75.0 & 80.0 \\
\hline & 7 Microcrack,Radial Crack, & $15.5,65$ & 65.0 & 80.0 \\
\hline & 8 Microcrack, & 35.9 & na & na \\
\hline & 9 Microcrack,Radial Crack, & $34.9,67.1$ & 67.1 & 80.0 \\
\hline & 10 Microcrack,Radial Crack,Repair, & $21.3,47.2,48.1$ & 47.2 & 48.1 \\
\hline & 11 Microcrack, & 37.5 & na & na \\
\hline & 12 Microcrack, & 39, & na & na \\
\hline & 13 Microcrack, & 29.1, & na & na \\
\hline & 14 Microcrack, Radial Crack,Leak, & $23.9,46.1,75.7$ & 46.1 & 80.0 \\
\hline
\end{tabular}


Throughout a vulnerability window, the component rupture pressure is estimated using Equation 4.17 based on the time-dependent crack depth in each sample member. Figure 5-1 shows the time-dependent component failure pressures for each sample member. The decreasing failure pressure in each sample member reflects the growing crack size. Where a curve displays a minimum and subsequent increase, then a repair transition has occurred. As discussed, for radial macro-cracks, the rupture pressure is not allowed to fall below $20 \mathrm{MPa}$.

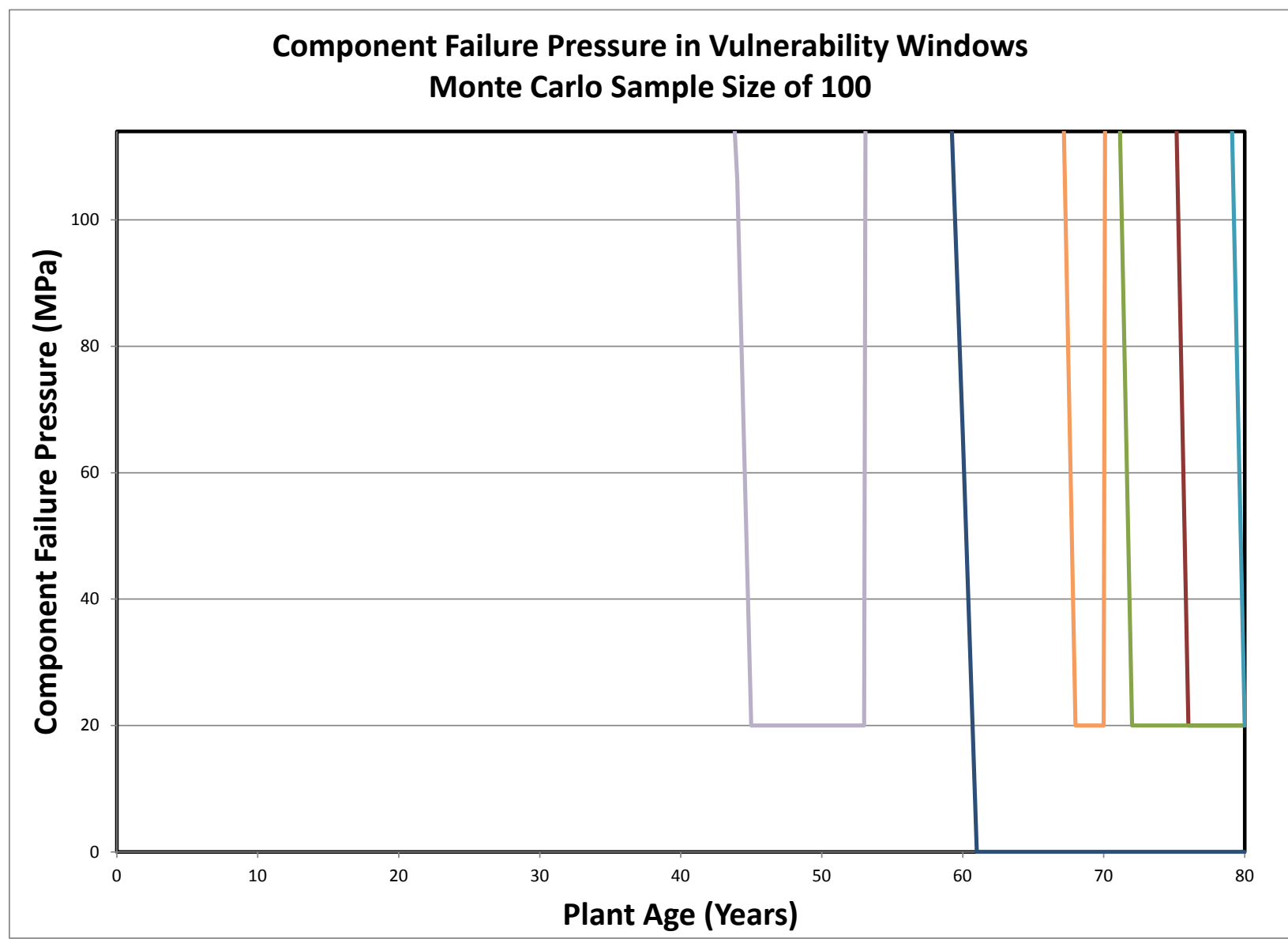

Figure 5-1 Failure Pressures Associated with a Sample of State Transition Histories

If this sample were generated as part of a broader physics parameter sample in an R7 analysis, then the system operating pressure history in each sample member would be compared to the component failure pressure history in that same sample member to determine whether and when component rupture occurs. 
Physics-Based SCC Reliability Model in a Cumulative Damage Framework

\section{References}

[1] U.S. Department of Energy, "Light Water Reactor Sustainability Research and Development Program Plan. Fiscal Year 2009-2013," September 2009.

[2] R. Nourgaliev and R. Nelson, R7 VU Born-Assessed Demo Plan, INL/EXT-10-17979, February 2010.

[3] R. Nourgaliev, N. Dinh, and R. Youngblood, "Development, Selection, Implementation, and Testing of Architectural Features and Solution Techniques for Next Generation of System Simulation Codes to Support the Safety Case of the LWR Life Extension," September 30, 2010.

[4] S.D. Unwin, P.P. Lowry, R.F. Layton, P.G. Heasler, and M.B. Toloczko, "Multi-State Physics Models of Aging Passive Components in Probabilistic Risk Assessment," Proceedings of the International Topical Meeting on Probabilistic Safety Assessment and Analysis: PSA2011, Wilmington, NC, 2011,

[5] W.J. Shack, O.K. Chopra, Statistical Initiation and Crack Growth Models for Stress Corrosion Cracking, Proceedings of the Pressure Vessels and Piping Conference (PVP2007), ASME, July 22-26, 2007, San Antonio, Texas, pp. 337-344.

[6] Statistical Analysis of Steam Generator Tube Degradation, EPRI NP-7493, 1991.

[7] Bases for Predicting the Earliest Penetrations Due to SCC for Alloy 600 on the Secondary Side of PWR Steam Generators, NUREG/CR-6737, U.S. Nuclear Regulatory Commission, 2001.

[8] F. Cayelo, J.L. Gonzales, and J.M. Hallen, "A Study on the Reliability Assessment Methodology for Pipelines with Active Corrosion Defects", International Journal of Pressure Vessels and Piping, Volume 79 (2002) pages $77-86$.

[9] D.O. Harris and D. Dedhia. 1992. Theoretical and User's Manual for pc-PRAISE, A Probabilistic Fracture Mechanics Code for Piping Reliability Analysis, An updated version of NUREG/CR-5864, Engineering Mechanics Technology, Inc. San Jose, California.

[10] R.W. Youngblood, R.R. Nourgaliev, D.L. Kelly, C.L. Smith, and T-N Dinh, "Heartbeat Model for Component Failure Time In Simulation Of Plant Behavior" ANS PSA 2011 International Topical Meeting on Probabilistic Safety Assessment and Analysis Wilmington, NC, March 1317, 2011, on CD-ROM, American Nuclear Society, LaGrange Park, IL (2011)

[11] K.N. Fleming, "Markov models for evaluating risk-informed in-service inspection strategies for nuclear power plant piping systems," Reliability Engineering and System Safety, 83 pp. 2745 (2004).

[12] M. Kamaya, T. Haruna, "Crack Initiation Model for Sensitized 304 Stainless Steel in High Temperature Water”, Corrosion Science, Vol. 48, 2006, pp. 2442-2456.

[13] O.F. Aly, et al., "Preliminary Study for Extension and Improvement on Modeling of Primary Water Stress Corrosion Cracking at Control Rod Drive Mechanism Nozzles of Pressurized Water Reactors", International Nuclear Atlantic Conference (INAC) 2009, Rio de Janeiro. 
Physics-Based SCC Reliability Model in a Cumulative Damage Framework

[14] P. Scott, et al., "Comparison of Laboratory and Field Experience of PWSCC in Alloy 182 Weld Metal", 13th International Conference on Environmental Degradation of Materials in Nuclear Power Systems, Whistler, BC, August 2007.

[15] S. Le Hong, J. M. Boursier, C. Amzallag, and J. Daret, "Measurements of Stress Corrosion Cracking Growth Rates in Weld Alloy 182 in Primary Water of PWR," Proceedings of 10th International Conference on Environmental Degradation of Materials in Nuclear Power Systems-Water Reactors, NACE International, 2002.

[16] Jong-Dae Hong, C. Jang, "Probabilistic Fracture Mechanics Application for Alloy 82/182 Welds in PWRs", Proceedings of the ASME Pressure Vessel and Piping Division / K-PVP Conference Paper PVP2010-25176, Bellevue, Washington, July 2010.

[17] Crack Growth of Alloy 182 Weld Metal in PWR Environments (PWRMRP-21), EPRI, Palo Alto, CA, 2000, 1000037.

[18] Materials Reliability Program Crack Growth Rates for Evaluating Primary Water Stress Corrosion Cracking (PWSCC) of Alloy 82,182, and 132 Welds (MRP-115), EPRI, Palo Alto, CA, 2003, 1006696.

[19] B. Alexandreanu, O.K. Chopra, and W.J. Shack, "Crack Growth Rates and Metallographic Examinations of Alloy 600 and Alloy 82/182 from Field Components and Laboratory Materials Tested in PWR Environments", (NUREG 6964 / ANL-07/12) Office of NRR, May 2008

[20] "Materials Reliability Program: Review of Stress Corrosion Cracking of Alloys 182 and 82 in PWR Primary Water Service" (MRP-220). EPRI, Palo Alto, CA: 2007. 1015427.

[21] Park, In-Gyu, "Primary water stress corrosion cracking behaviors in the shot-peened Alloy 600 TT Steam Generator Tubings", Nuclear Engineering and Design 2002, Volume 212, pages $395-399$

[22] M.A. Khaleel and F.A. Simonen, "Evaluations of Structural Failure Probabilities and Candidate Inservice Inspection Programs", USNRC: Pacific Northwest National Laboratory, Richland, WA, 2009 (NUREG/CR-6986; PNNL-13810)

[23] "Materials Reliability Program: Probabilistic Risk Assessment of Alloy 82/182 Piping Butt Welds" (MRP-116NP). EPRI, Palo Alto, CA: October 2004. 1009806. 


\section{Appendix 1: Physics Models}

The objective of developing the physics-based multi-state model was not to identify and integrate the most detailed and rigorous models available but, rather, to demonstrate the principle and feasibility of incorporating physics models into multi-state reliability models and then implementing them in a cumulative damage framework. Furthermore, the physics models incorporated into the preliminary multi-state model focus on a limited set of phenomena - in particular, stress corrosion cracking (SCC) crack initiation and crack growth - with the understanding that these models will ultimately be supplemented to address the wider phenomenology relevant to aging reliability.

In this section, we outline the contributing physics models. The means of their incorporation into the cumulative damage framework is described in Section 4 of the main report.

\section{A1.1 Stress Cracking Corrosion Initiation}

SCC initiation is the nucleation of a stress corrosion crack. A stress corrosion crack is considered nucleated when the crack can be described by crack growth rate models $[5-7,12$, and 18]. A grain boundary in a weld is defined as the boundary between packets of dendrites with malformed angular orientations. These are the preferred locations for SCC initiation and growth in Alloys 182 and 82 [18]. Similar to other nucleation and growth phenomena, SCC cracking is generally modeled as, first, a nucleation step governed by statistical processes, and then as crack growth that has a more deterministic basis. The probability of nucleation is controlled by preexisting surface flaws in the weld and by the rate of formation of surface flaws due to the fabrication process and environment. Published models of crack initiation typically do not attempt to define initial flaw characteristics, since, because of the practical difficulty in identifying a surface flaw, such a model could not be quantified [18].

A number of alternative models have been used to characterize initiation [5 - 7, 12 - 14], the Weibull model being the most widely adopted [5-7, 12, and 22]. In the Weibull model, the cumulative probability of crack initiation by time $t, F(t)$, is given by

Where:

$\eta_{l} \quad$ crack initiation time constant - Weibull scale parameter (yrs)

$\gamma \quad$ fitting parameter - Weibull shape parameter.

The time constant $\left(\eta_{1}\right)$ has been observed to have both a stress and temperature dependence, and can be expressed as 
where:

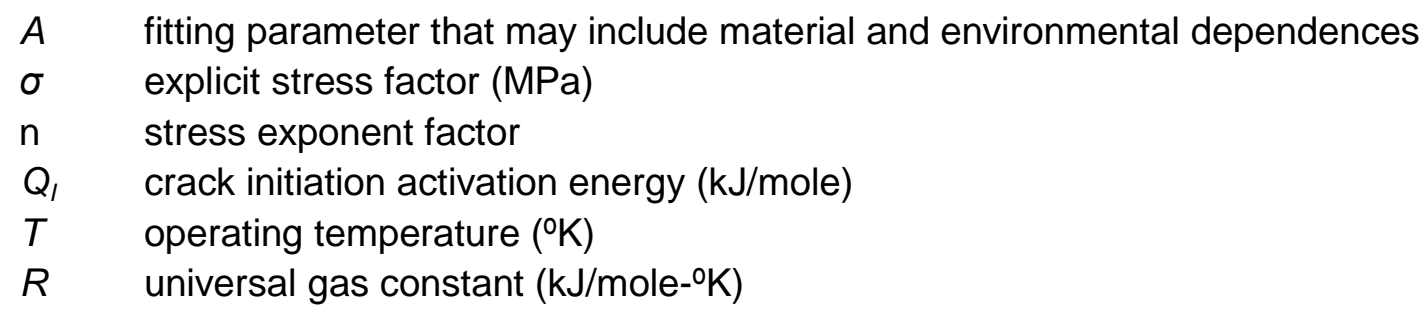

One study [13] provides the following equation for $\left(\eta_{1}\right)$ as a function of operating temperature (T) and total stress in the vicinity of the crack $(\sigma)$.

Reference [14] suggests a stress exponent of (-7) for Alloy 182 and (-6) for Alloy 82. Activation energy $\left(Q_{I}\right)$ was estimated to be $129 \mathrm{~kJ} /$ mole [14].

A general plot of cumulative probability $F(t)$ is shown in Figure A1-1 and depicts the effect of an increasing Weibull shape parameter on the probability evolution. Because of difficulties in measuring SCC initiation, well-defined values for the fitting parameters do not exist for Alloy 182/82 (or most other reactor coolant system materials).

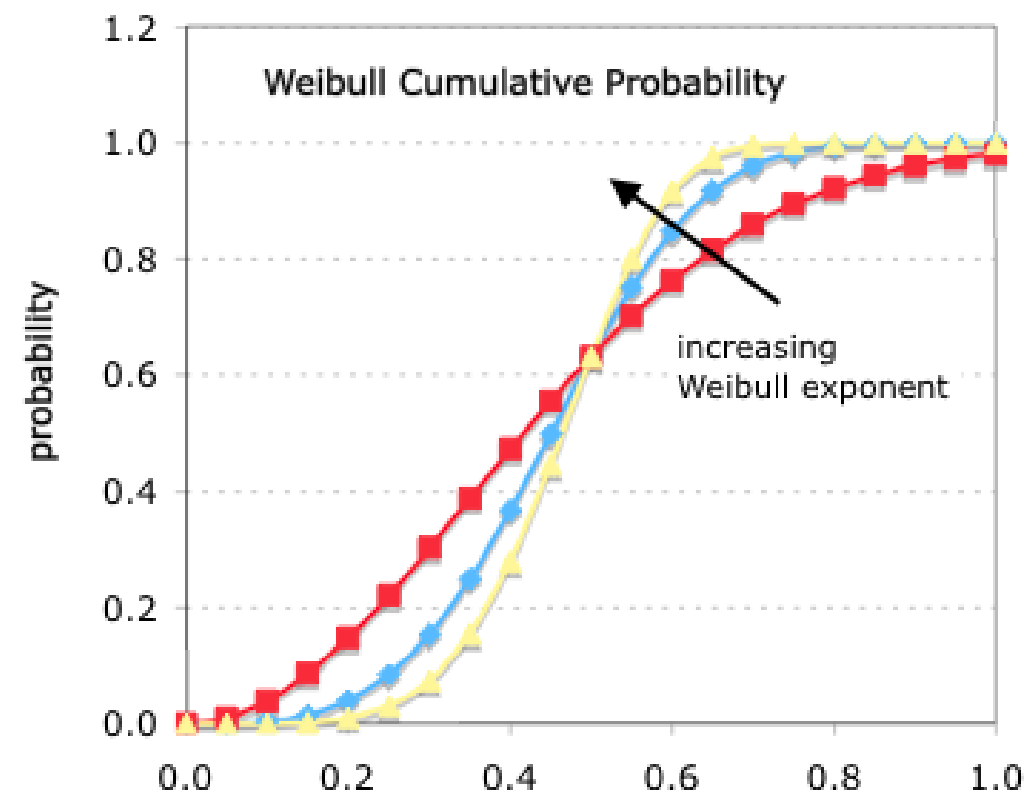

Figure A1-1 Example Weibull cumulative probability plot for crack initiation - the horizontal axis is a scaled time variable 
Published material on crack initiation is very limited [12, 13, 16, and 21]. Specific studies at 182/82 weld sites [16] based on the Weibull distribution for crack initiation provide an estimated value for the shape factor $(\gamma)$ of 4.35 using accumulated in-situ data.

Total stress at the crack site consists of two elements of stress; operating pressure stress $\left(\sigma_{o p}\right)$ and residual or bending stress $\left(\sigma_{\text {res }}\right)$, and the bases for their estimation is discussed in Section A1.2.

\begin{tabular}{|l|r|}
\hline$\sigma_{\text {op }}$-operating stress (MPa) & 30.3 \\
\hline$\sigma_{\text {res }}$-residual stress (MPa) & 75.7 \\
\hline total stress (MPa) & 106.0 \\
\hline
\end{tabular}

Based on these estimated stresses, the baseline crack initiation Weibull parameter values used in this analysis were $\mathrm{y}=4.35$ and $\eta_{l}=11,493$ yrs.

\section{A1.2 Stress Cracking Corrosion Crack Growth}

Data compilations for Alloy 182/82 SCC crack growth rates, along with phenomenological SCC crack growth rate models, have been generated by numerous teams including Shack et al. [5], Aly et al. [13], Hong et al. [15], EPRI [17, 18, 20, 23], and NRC [7, 9, 19, and 22]. All the models have a similar form that includes a stress and Arrhenius temperature dependence. EPRI report MRP-220 [20] is the most recent report with a comprehensive data set and is therefore used for current purposes. The equation used in that report is:

Where:

crack growth rate $(\mathrm{m} / \mathrm{s})$

fitting constant - crack growth amplitude - lognormal distribution

$T \quad$ operating temperature at crack location ( ${ }^{\circ} \mathrm{K}$ )

$T_{\text {ref }} \quad$ reference temperature used to normalize data $\left({ }^{\circ} \mathrm{K}\right)$

$Q_{G} \quad$ thermal activation energy for crack growth ( $\left.\mathrm{kJ} / \mathrm{mole}\right)$

$R \quad$ universal gas constant $(\mathrm{kJ} /$ mole- $\mathrm{K})$

$K \quad$ crack tip stress intensity factor $(\mathrm{MPa} \sqrt{ } \mathrm{m})$

$f_{\text {alloy }} 1.0$ for Alloy 182

$f_{\text {orient }} 1.0$ (parallel to dendrite solidification direction)

$\beta \quad$ stress intensity exponent (1.6). 
Research on SCC $[13,19,20$, and 22] has resulted in estimates of the variables of Equation A1.4, which are now discussed.

\section{A1.2.1 Activation Energy Value $\left(Q_{G}\right)$}

For activation energy, the original model [18] assumed $130 \mathrm{~kJ} / \mathrm{mole}$. This is the same activation energy that was applied to the crack growth rate data for Alloy 600 . It was originally judged that there were insufficient data to develop reliable activation energy values for Alloy 182/132 and for Alloy 82 , so the activation energy value for Alloy 600 , which has a similar composition, was recommended for use with Alloys 82,182 , and 132 . However, more recent investigation concludes that activation energies for Alloy 182/82 crack growth should be more in the range of 210 to $240 \mathrm{~kJ} / \mathrm{mole}$ [20]. These values of activation energy were used in the crack growth model.

The sensitivity of growth rate to variations of activation energy in the range 210 to $240 \mathrm{~kJ} / \mathrm{mole}$ was determined to be minor. For the purposes of this analysis, the activation energy was assumed to be $210 \mathrm{~kJ} / \mathrm{mole}$.

\section{A1.2.2 Fitting Constant - Crack Growth Amplitude $(\varepsilon)$}

High variability is observed in the measured crack growth rates of Alloys 82 and 182 due to metallurgical variability. This variability is treated stochastically in our model (see Section 4 of main report). There are numerous estimates of the fitting constant for growth amplitude $\varepsilon$ in the literature. In recent research, the fitting constant is assessed to be log-normally distributed with a median value of approximately 8E-13 [19]. For our model, the fitting constant was bracketed at the 5th and 95th percentiles of the lognormal distribution. 


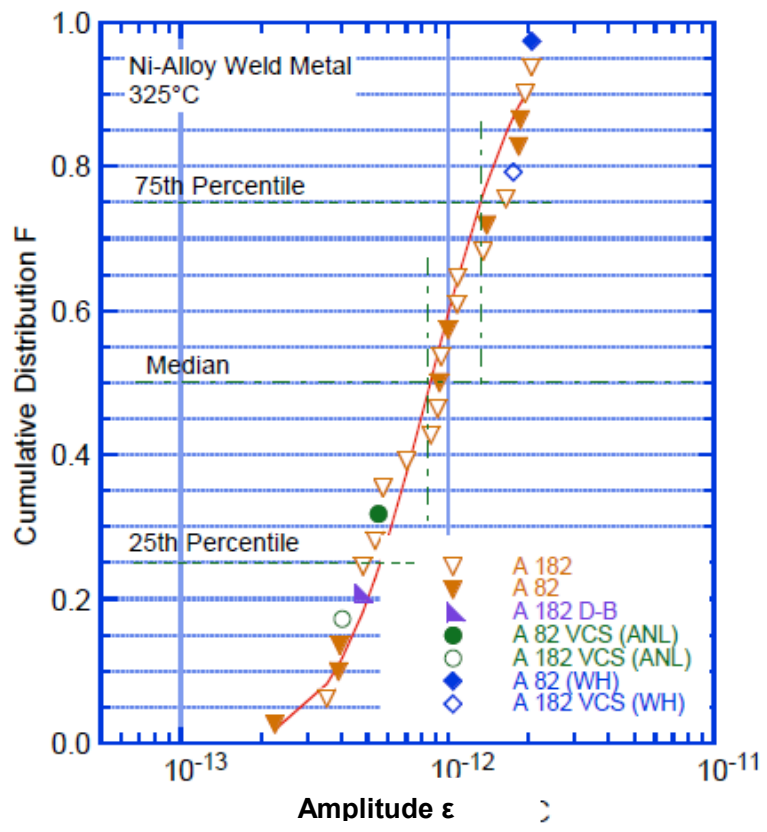

Figure A1-2 Log-normal Distribution of Crack Growth Amplitude $\varepsilon$ for Alloys 82 and 182 - NUREG 6964 [17]

\section{A1.2.3 Stress Intensity Factor $(K)$}

Stress intensity factor $(K)$ solutions have been developed for specific crack geometries and applied stress distributions based on both analytical solutions and finite element numerical methods. Stress intensity solutions for finite-depth flaws under complex stress distributions (uniform and linear distributions) of interest in pipes and welds have generally been solved using finite element numerical methods. SCC rates are reported to be sensitive to the applied stress, and therefore models predicting SCC over time need to include the variation of $\mathrm{K}$ with increasing flaw depth and length.

A set algorithms for estimating stress intensity factors is part of the pc-PRAISE code [9]. These algorithms were used in the current analysis to support estimates of stress intensity (see Appendix 2). The crack tip stress intensity factor, $\mathrm{K}$, is a function of the crack geometry and the applied stresses. $\mathrm{K}$ increases significantly with the crack depth which in turn increases the SCC growth rate as the crack deepens. K can be represented as:

where: 


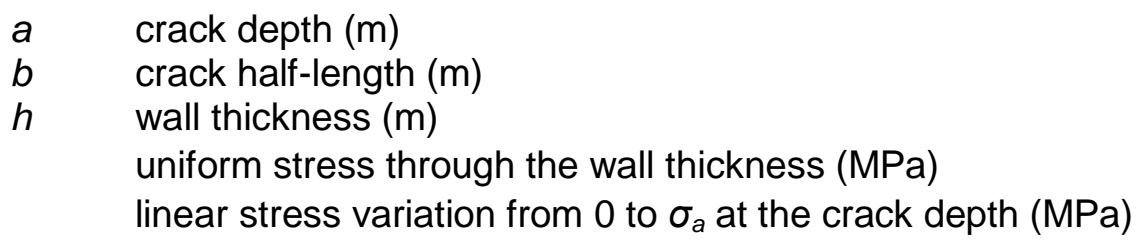

Figure A1-3 shows the crack geometry in the pipe wall.

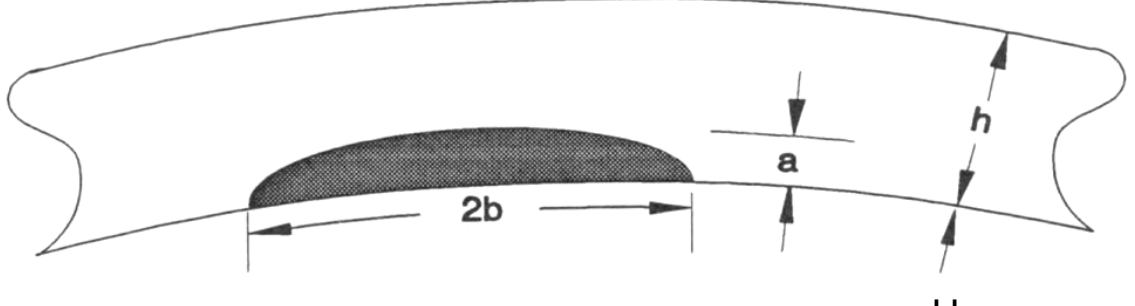

$\mathrm{H}$

Figure A1-3 Geometry of a finite length, partial through-wall crack

Two crack growth morphologies were analyzed reflecting differing aspect ratios (depth-length ratio):

- $\quad$ A "half-penny" flaw $(a / b=1.0)$ representing the radial crack propagation

- $\quad$ A "long" flaw crack $(a / b=0.1)$ representing the circumferential crack propagation.

There are two contributions to the stress distribution through the pipe wall. The first is a uniform axial stress across the wall associated with the plant operating pressure at the weld location, and the second is a linear residual or bending stress considered to start on the inside of the wall at twice the uniform axial stress. Plant operating pressures $(10-18 \mathrm{MPa})$ were used to determine axial and bending/residual stress values at the crack site. The following stress estimates were used as reasonable approximations:

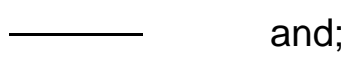

where:

$\sigma_{\text {op }} \quad$ operating pressure stress (MPa)

$\sigma_{\text {residual }}$ residual stress $(\mathrm{MPa})$

$P_{\text {op }} \quad$ operating pressure (MPa)

$H \quad$ pipe diameter $(\mathrm{m})$

$h \quad$ pipe wall thickness $(\mathrm{m})$.

Assuming $\mathrm{P}_{\mathrm{op}}=15.1 \mathrm{MPa}, H=0.3048 \mathrm{~m}$, and $h=0.038 \mathrm{~m}$, we produce the following stress estimates in the base operating case. (These estimates are also used in the crack initiation formulation - Section A1.1.) 


\begin{tabular}{|l|r|}
\hline$\sigma_{\text {op }}$-operating stress (MPa) & 30.3 \\
\hline$\sigma_{\text {residual }}$-residual stress (MPa) & 75.7 \\
\hline total stress (MPa) & 106.0 \\
\hline
\end{tabular}

\section{A1.2.4 Aleatory Analysis}

In an R7 setting, repeated use of pc-PRAISE for stress intensity calculations is not practical. Therefore, simplified models were developed that are rapidly implementable in the cumulative damage model environment. Two types of physical variables are considered: those exogenous to the crack growth model; i.e., those that will be established by the R7 environment, and those that are endogenous to the crack growth model. The exogenous parameters are the operating temperature and pressure at the component. The remaining parameters are considered to be endogenous. Note that Equation A1.4 for crack growth rate is deterministic. However, if we consider some of the input parameters to Equation A1.4 to behave stochastically (due to aleatory variability in weld metallurgy, for example ), then the crack growth rate becomes a stochastic variable. The stochastic modeling of crack growth and the development of simplified macro-crack transition models is described in Section 4.

\section{A1.3 Transition Split Probability: Radial versus Circumferential Crack}

SCC cracks are more likely to grow on grain boundaries parallel to the dendrites, i.e. in the "through wall" direction (radial). Initiation and propagation is least likely perpendicular to the general direction of the dendrites (circumferential). The ratio of the number of radial to circumferential flaws can be obtained from service experience [20]. There is a large data base of cracks found in Alloy 600 and Alloy 82/182 materials over the past 20 years. The largest number of cases occurred in the small-diameter pipes, but there is also experience with the reactor vessel outlet nozzle regions. In total, there are over 100 cracking incidents, and only one or two circumferential flaws [20].

Studies indicate cracking in Alloys 182 and 82 was not observed in operating PWR plants until the year 2000, when several incidents occurred. Prior to 2003 , all recorded cracks in smalldiameter nozzles and heater sleeves installed with partial penetration welds, with one exception, were radially oriented [18]. There have been a total of five events involving cracks in largediameter pipes (one circumferential and four radial). If these are added to the cracks found in small bore pipes, the ratio of radial to circumferential flaws is about 100 to 1 . This is the empirical basis for estimating the split probability of transitions from the microcrack state to the radial macrocrack or circumferential macrocrack state.

Crack growth behavior is analyzed using Equation A1.4 for both radial and circumferential cracks. The crack growth analyses are described in Appendix 2. 


\section{A1.4 Pipe Rupture}

The rupture model used in the current analysis determines pipe failure pressure as a function of ultimate tensile strength and pipe wall thickness reduction. The limit state function $L S F\left(P_{f}\right)$ is defined as:

where:

$\mathrm{P}_{\mathrm{f}} \quad$ = pipe failure pressure $(\mathrm{MPa})$

$\mathrm{P}_{\mathrm{op}} \quad=$ operating pressure $(\mathrm{MPa})$.

When $\operatorname{LSF}\left(P_{f}\right)$ is positive the pipe remains intact. Rupture occurs when $\operatorname{LSF}\left(P_{f}\right)$ becomes negative. The rupture pressure estimate $P_{f}$ is based on the Battelle pipe failure model [8], although adapted to address failure criteria associated with axial stress:

where

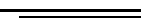

(A1.10)

and

$\mathrm{P}_{\mathrm{f}} \quad$ rupture pressure (MPa)

$\sigma_{\mathrm{F}} \quad$ material flow stress (MPa)

$\mathrm{H}$ pipe diameter $(\mathrm{m})$

$\mathrm{h} \quad$ pipe thickness $(\mathrm{m})$

b crack semi-length $(\mathrm{m})$

a crack depth (m)

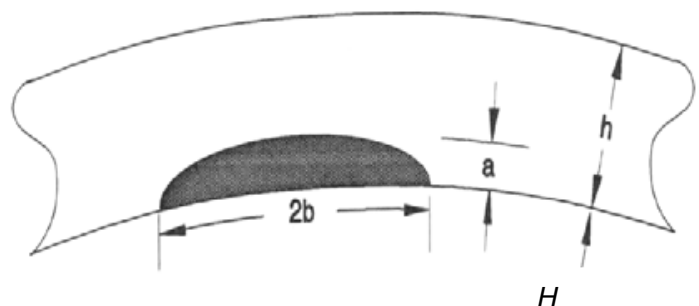

H

Figure A1-4 Crack Geometry

For our analysis, these parameters are quantified as $H=0.3048 \mathrm{~m}, h=0.038 \mathrm{~m}, \sigma_{F}=333 \mathrm{MPa}$, while the crack length and depth ( $b$ and $a$ ) emerge from the crack growth model. Means of implementing this rupture model are described in Section 4.

\section{A1.5 References}

Reference numbers in this appendix refer to the listing in the main report (Section 6). 


\section{Appendix 2: Stress Intensity Solutions}

\section{Stress Intensity Factor Solutions as a function or Crack Geometry and Stress Distribution}

Stress intensity factor $\left(\mathrm{K}_{\mathrm{l}}\right)$ solutions have been developed for specific crack geometries and applied stress distributions using both analytical solutions and finite element numerical methods. The analytical solutions are possible for only a few idealized boundary conditions and simple stress distributions. $K_{1}$ solutions for finite-length flaws under complex stress distributions (uniform, linear, and quadratic stress distributions) that are of interest in pipes and pressure vessels have been solved using finite element numerical methods. Pressured water stress corrosion cracking (PWSCC) rates are reported to be sensitive to the applied $\mathrm{K}_{\mathrm{l}}$, and therefore models predicting PWSCC over time should include the variation of $\mathrm{K}_{\mathrm{I}}$ with increasing flaw depth and length.

A set of $\mathrm{K}_{1}$ solutions is available from the pc-PRAISE code documentation Harris and Dedhia [A2.1]. Figure 1 shows the definition of the crack geometry in a pressure vessel wall. Equations 1 and 2 of Appendix 2 approximate $K_{1}$ as a function of crack depth, $a$, and length, $2 b$, in an infinite plate of thickness, $h$, for uniform and linearly varying stress distributions. These equations define the $\mathrm{K}_{\mathrm{I}}$ values for crack growth in the depth "a" direction and crack growth in the length "b" direction (see Figure 1 ) in terms of the variables $\boldsymbol{\alpha}=\mathbf{a} / \boldsymbol{h}$ and $\boldsymbol{\zeta}=\mathbf{a} / \mathbf{b}$. Figure 2 shows the definitions of the uniform and linear stress components.

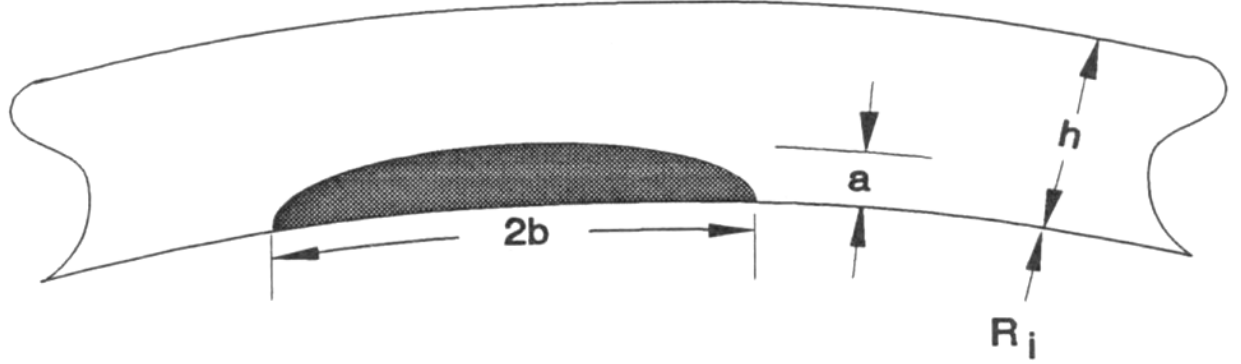

Figure 1. Crack Geometry of a partial through-wall, finite length crack.

The pc-Praise solutions are the RMS average $K_{1}$ values along the crack front. These solutions differ somewhat from the point-wise solutions presented in other sources. However, they give the general trends of increasing $K_{1}$ with crack depth and load. Harris and Dedhia [A2.1] make the case that since $K_{1}$ actually varies along the crack front, the RMS values are a good approximation of a crack that grows with a constant $\mathrm{a} / \mathrm{b}$ aspect ratio. The routines from $\mathrm{pc}$ PRAISE have been included in a driver program to calculate $K_{1}$ for further development of the RISMC analytical methods of estimating progressive PWSCC. The FORTRAN source is listed at the end of this document. The $\mathrm{K}_{\mathrm{I}}$ solutions from pc-PRAISE were compared with other $\mathrm{K}_{\mathrm{I}}$ solutions to ensure that the routines were implemented correctly. Figures 3, 4, and 5 compare $\mathrm{K}_{\mathrm{I}}$ solutions for three different crack depth-to-length ratios: 
Physics-Based SCC Reliability Model in a Cumulative Damage Framework

1. A half-penny flaw $(a / b=1.0)$,

2. A $5: 1$ flaw $(a / b=0.4)$, and

3. A long flaw with $20: 1$ depth-to-length ratio $(a / b=0.1)$.

Equation 1. RMS stress intensity factor coefficients for crack growth in the "a" or "b" directions for a uniform stress, $\sigma . \alpha=a / h$ and $\zeta=a / b$.

$$
\begin{aligned}
& \frac{\overline{K_{a}}}{\sigma a^{1 / 2}}=\left[\left(1.8781-0.7248 \zeta-0.2035 \zeta^{2}+0.2432 \zeta^{3}\right)\right. \\
& +\left(-1.9181+0.4252 \zeta+8.0667 \zeta^{2}-7.4870 \zeta^{3}\right) \alpha \\
& +\left(7.1762-11.3209 \zeta-10.4922 \zeta^{2}+15.9368 \zeta^{3}\right) \alpha^{2} \\
& \left.+\left(-6.0324+10.4690 \zeta+2.0322 \zeta^{2}-7.6101 \zeta^{3}\right) \alpha^{3}\right] /(1-\alpha)^{1 / 2} \\
& \overline{K_{b}} \\
& \overline{\sigma a^{1 / 2}}=\left[\left(1.3003+0.1046 \zeta-0.1943 \zeta^{2}+0.03935 \zeta^{3}\right)\right. \\
& +\left(-1.3745+0.7675 \zeta-1.3837 \zeta^{2}+1.5430 \zeta^{3}\right) \alpha \\
& +\left(4.0255-7.0179 \zeta+10.6008 \zeta^{2}-7.7883 \zeta^{3}\right) \alpha^{2} \\
& \left.+\left(-3.2410+5.3097 \zeta-7.8403 \zeta^{2}+5.4374 \zeta^{3}\right) \alpha^{3}\right] /(1-\alpha)^{1 / 2}
\end{aligned}
$$

Equation 2. Stress intensity factor coefficients for crack growth in the "a" or "b" directions for a linear stress distribution equal to zero at the inside wall and $\sigma_{a}$ at crack depth a. $\boldsymbol{\alpha}=\boldsymbol{a} / \boldsymbol{h}$ and $\zeta=a / b$

$$
\begin{aligned}
& \frac{\overline{K_{a}}}{\sigma_{a} a^{1 / 2}}=\left[\left(1.01392-0.78506 \alpha+3.31506 \alpha^{2}-0.991159 \alpha^{3}\right)\right. \\
& +\left(-0.34032+2.5896 \alpha-9.02996 \alpha^{2}+2.88101 \alpha^{3}\right) \zeta \\
& \left.+\left(0.045722-1.90305 \alpha+6.05041 \alpha^{2}-1.93187 \alpha^{3}\right) \zeta^{2}\right]
\end{aligned}
$$

(Equation 2)

$$
\begin{aligned}
& \frac{\overline{K_{b}}}{\sigma_{a} a^{1 / 2}}=\left[\left(0.47954-0.206885 \alpha+1.112738 \alpha^{2}-0.19908 \alpha^{3}\right)\right. \\
& +\left(-0.0249092+0.144091 \alpha-1.61755 \alpha^{2}-0.176543 \alpha^{3}\right) \zeta \\
& +\left(0.0450383-0.223205 \alpha+1.97511 \alpha^{2}+0.779899 \alpha^{3}\right) \zeta^{2} \\
& \left.+\left(-0.04859+0.37304 \alpha-1.5687 \alpha^{2}-0.3790668 \alpha^{3}\right) \zeta^{3}\right]
\end{aligned}
$$




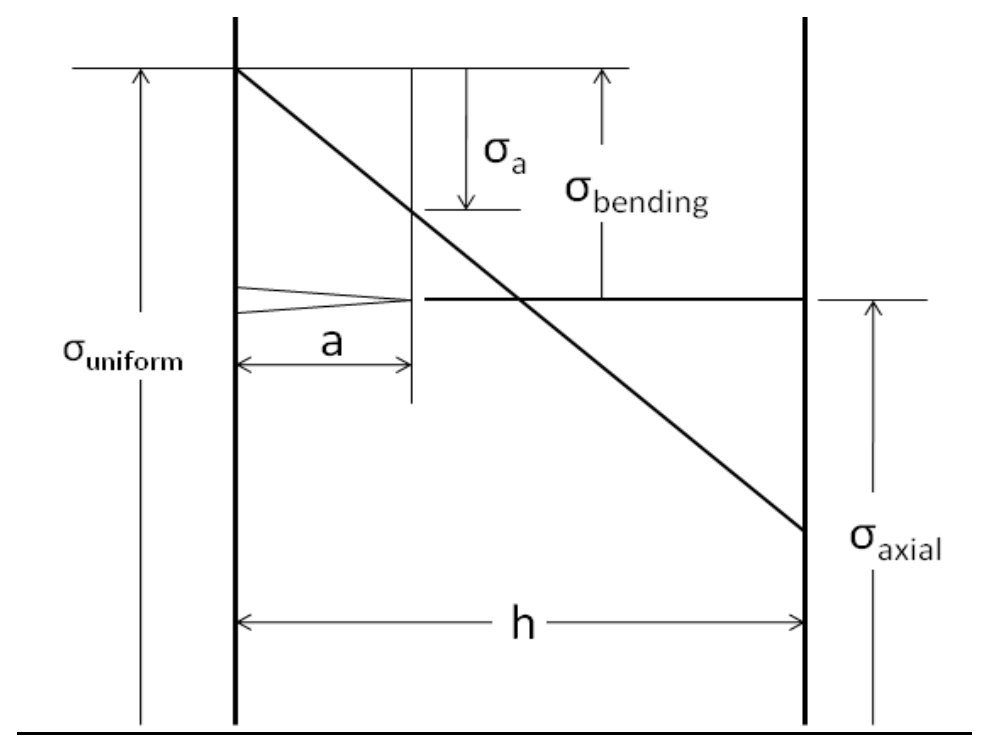

Figure 2. Definition of the Stress Distribution Through the Vessel Wall Thickness.

The stress intensity factor is often presented in the form:

$K_{I a}=\overline{K_{a U}} \sigma_{U} \sqrt{\pi a}+\overline{K_{a L}} \sigma_{a} \sqrt{\pi a}$

where: $\quad \overline{K_{a U}}$ is the uniform stress coefficient for crack growth, a, in equation 1 divided by $\sqrt{\pi}$

$\sigma_{U}$ is the uniform stress,

$\overline{K_{a L}}$ is the linear stress coefficient for crack growth, $a$, in equation 2 divided by $\sqrt{\pi}$, and

$\sigma_{a}$ is the stress at depth, $a$, which varies linearly from 0 at the inside surface.

The $\mathrm{K}_{\mathrm{I}}$ solutions by Rooke and Cartwright [A2.2] express the linear stress contribution as a function of the bending moment, where the surface stress is $\sigma_{\text {bend }}=6 M / h^{2}$. The $\mathrm{K}_{\mathrm{l}}$ coefficient, $K_{I a_{-} M}$, was calculated to compare with the Rooke and Cartwright moment solution.

$K_{I a_{-} M}=\overline{K_{a U}}-\overline{K_{a L}}(2 a / h)$

The data in Figures 3, 4, and 5 compare the $K_{1}$ solutions for crack growth in the throughthickness "a" direction:

\footnotetext{
SIFUA $\overline{K_{a U}}=$ PC-Praise $K_{1}$ uniform stress coefficient divided by $\sqrt{\pi}$, SIFLA $\overline{K_{a L}}=\mathrm{PC}$-Praise $\mathrm{K}_{\mathrm{l}}$ linear stress coefficient divided by $\sqrt{\pi}$, Moment-A The ${ }^{K_{I a} M}$ combination of SIFUA and SIFLA to compare with the Rooke and Cartwright coefficient of moment loading,
} 
F0A British R6 method, $K_{1}$ coefficient for uniform stress distribution, F1A British R6 method, $K_{1}$ coefficient for linear stress distribution,

$\mathrm{R} \& \mathrm{C}$, Uniform Stress Rooke and Cartwright $\mathrm{K}_{\mathrm{l}}$ coefficient for uniform stress distribution, $R \& C$, Linear Stress Rooke and Cartwright $K_{l}$ coefficient for a moment load, $M$.

Comparing SIFUA with FOA and the Rooke and Cartwright [A2.2] uniform stress coefficient shows that the values are different but with similar trends. Comparing SIFLA with F1A again shows similar trends. Comparing Moment-A with Rooke and Cartwright's solution for the moment loads also shows comparable trends but somewhat different values of the coefficients. Figure 6 is page D-6 from Appendix D of NUREG/CR-6674 [A2.3] which shows the RMS $K_{1}$ influence functions from the Tiffany code for flaws with $a / b=1$ and $a / b=1 / 2.5$ (similar to Figures 3 and 4). Tiffany uses the same equations as those in pc-PRAISE. The curves for $n=0$ and $n=1$ (the uniform and linear stress components) are the same as those in Figures 3 and 4.

The differences between pc-PRAISE and the other solutions is partially because pc-PRAISE uses the RMS average values compared to the discrete values (at crack-tip "a" in Figure 1) of the other methods. Other factors may include the level of mesh resolution and accuracy of the finite element solutions available at the time each of these solutions was developed. The solutions presented here were all developed during the 1980's and 1990's. The more recent work of Anderson et al. [A2.4, A2.5] provides updated $\mathrm{K}_{\mathrm{I}}$ solutions for a wider range of cylindrical and spherical geometries and crack aspect ratios. The conclusion from Figures 3 through 6 is that the pc-PRAISE solutions give $K_{1}$ coefficients that are similar to other published solutions and that the calculation routines have been implemented correctly. 
Physics-Based SCC Reliability Model in a Cumulative Damage Framework

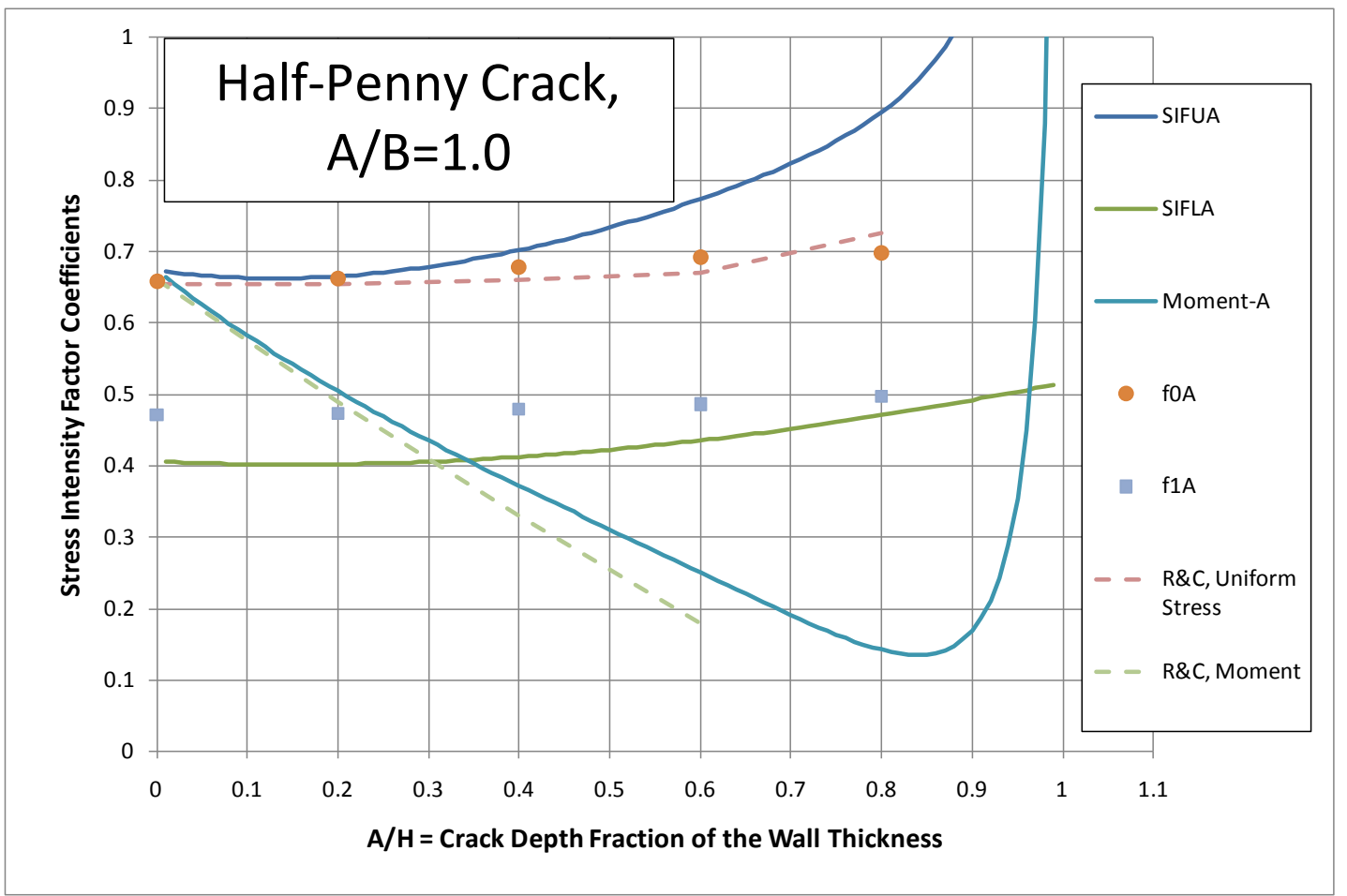

Figure 3. Comparison of Stress Intensity Factor Coefficients for the Half-Penny Surface Crack $(a / b=1.0)$.

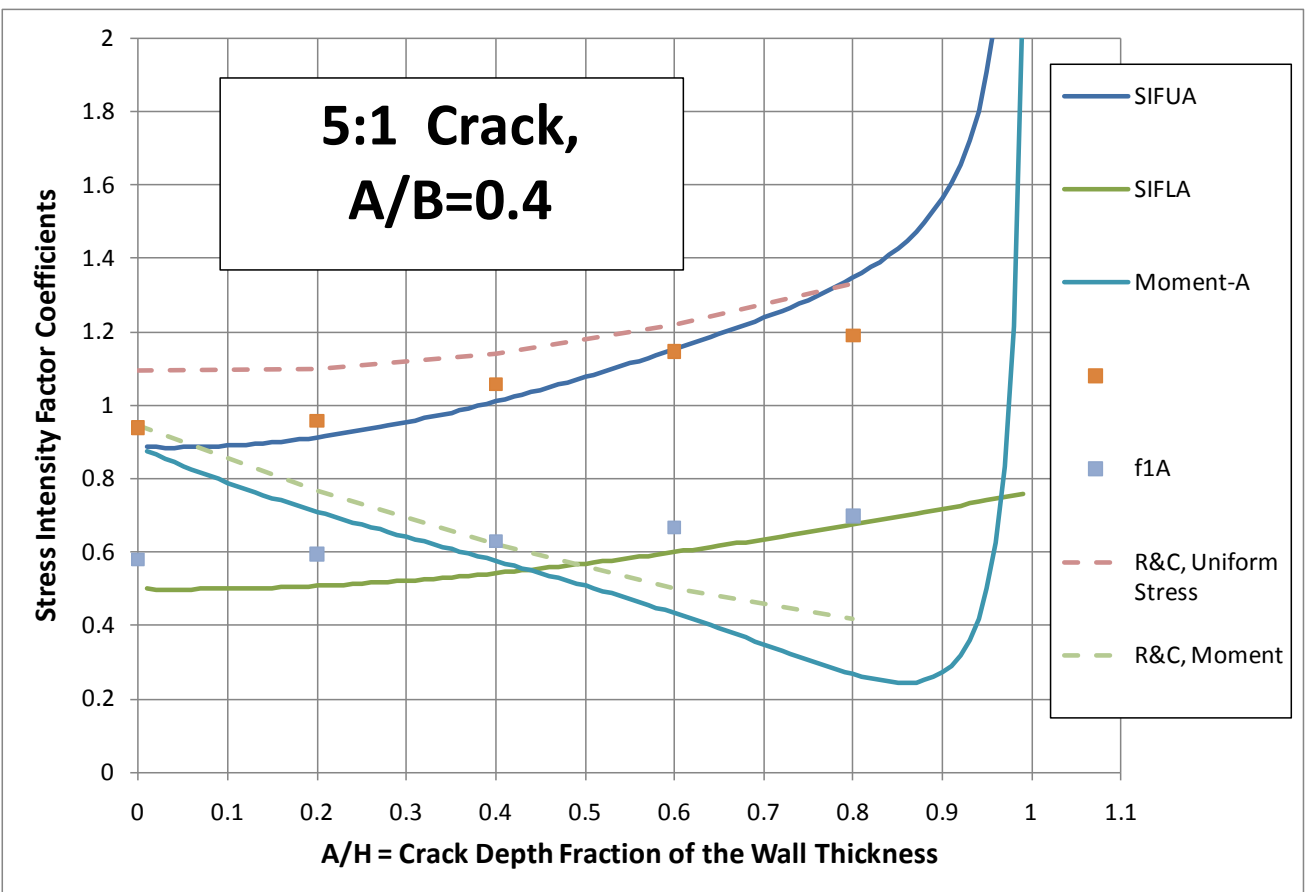

Figure 4. Comparison of Stress Intensity Factor Coefficients for the 2.5:1 Surface Crack $(a / b=0.4)$. 
Physics-Based SCC Reliability Model in a Cumulative Damage Framework

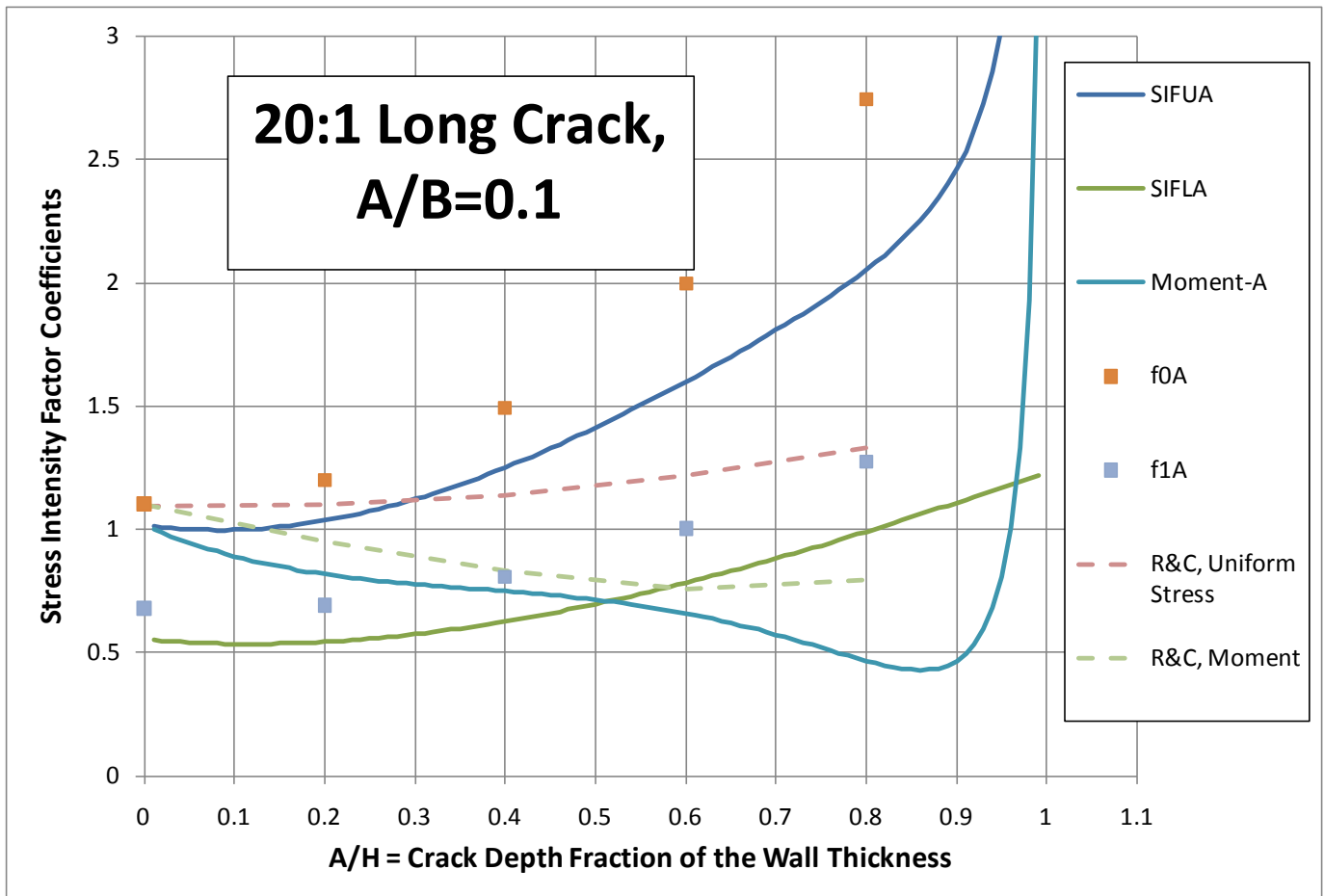

Figure 5. Comparison of Stress Intensity Factor Coefficients for the 20:1 Long Surface Crack $(a / b=0.1)$. 

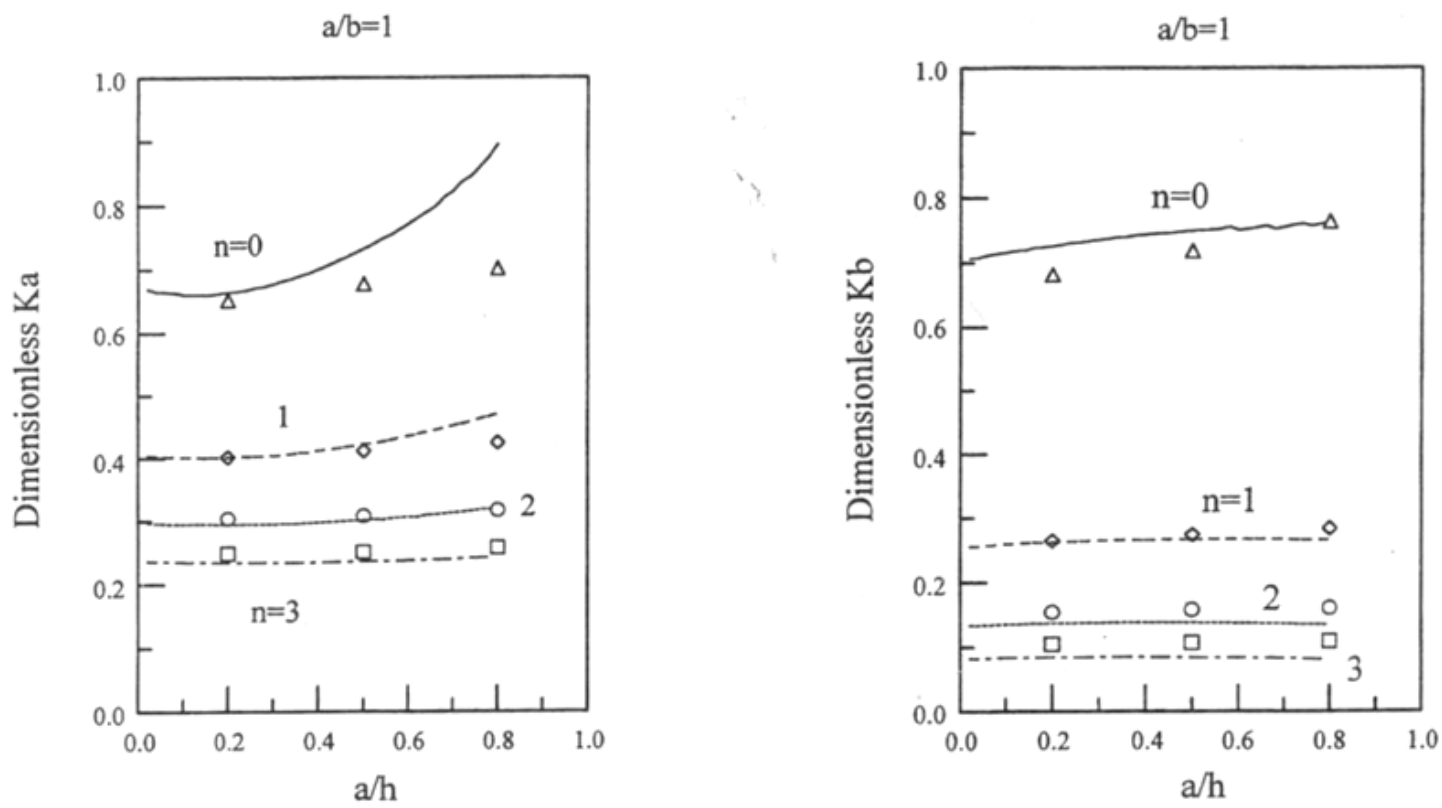

Figure D.3 Comparison of Raju-Newman RMS Values of $i_{n}$ with RMS Results from TIFFANY, $a / b=1$
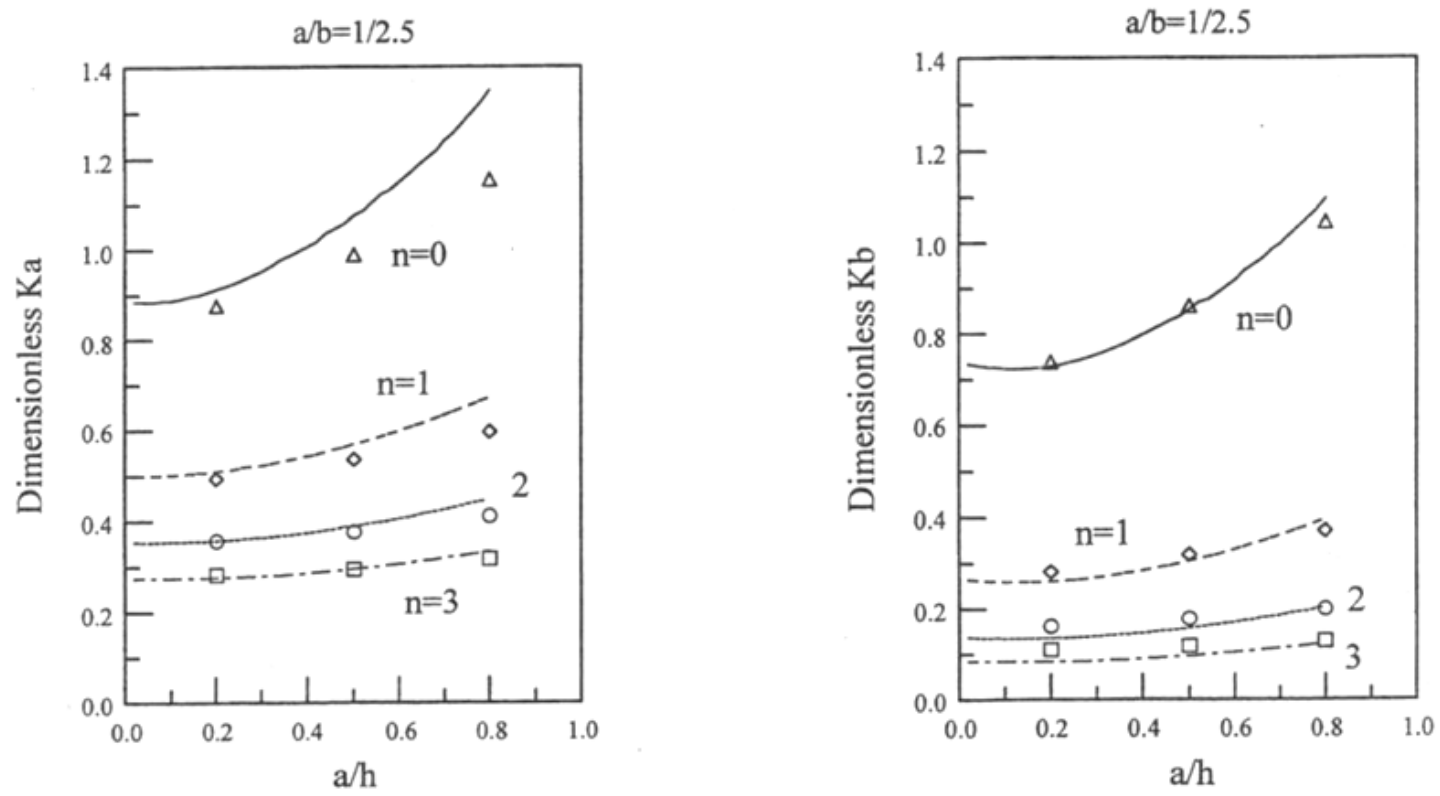

Figure D.4 Comparison of Raju-Newman RMS Values with RMS Results from TIFFANY, $\mathrm{a} / \mathrm{b}=1 / 2.5$

Figure 6. Stress intensity factor influence functions from the Tiffany code (Page D-6, NUREG/CR-6674 [A2.3]). Figures 3 and 4 reproduce the $n=0$ and $n=1$ curves on the left of dimensionless Ka.

Figures 7, 8, and 9 show stress intensity factors calculated using the pc-PRAISE influence functions. Axial stress in a pipe $(\sigma=p r / 2 t)$ was assumed as the load on a circumferential flaw. A $+/-10 \%$ variation in bending stress was also assumed through the wall thickness. The pipe 
dimensions, pressure, and stresses were intended to loosely approximate those of a pressurizer surge nozzle:

Pipe Inside Radius $=6.5$ inches

Pipe Wall Thickness $=1.5$ inches

Internal Pressure $=2250$ psi

Average Axial Stress $=4875$ psi

Bending Stress at Inside Surface $=+/-488$ psi

Figures 7, 8, and 9 show how $\mathrm{K}_{\mathrm{I}}$ increases significantly with crack depth. For the shorter cracks, Figures 7 and 8 also show that $K_{1}$ is higher for crack growth in the through-thickness direction compared to growth in the length direction. This is consistent with the tendency of short cracks to grow through the wall thickness rather than to first grow in length.

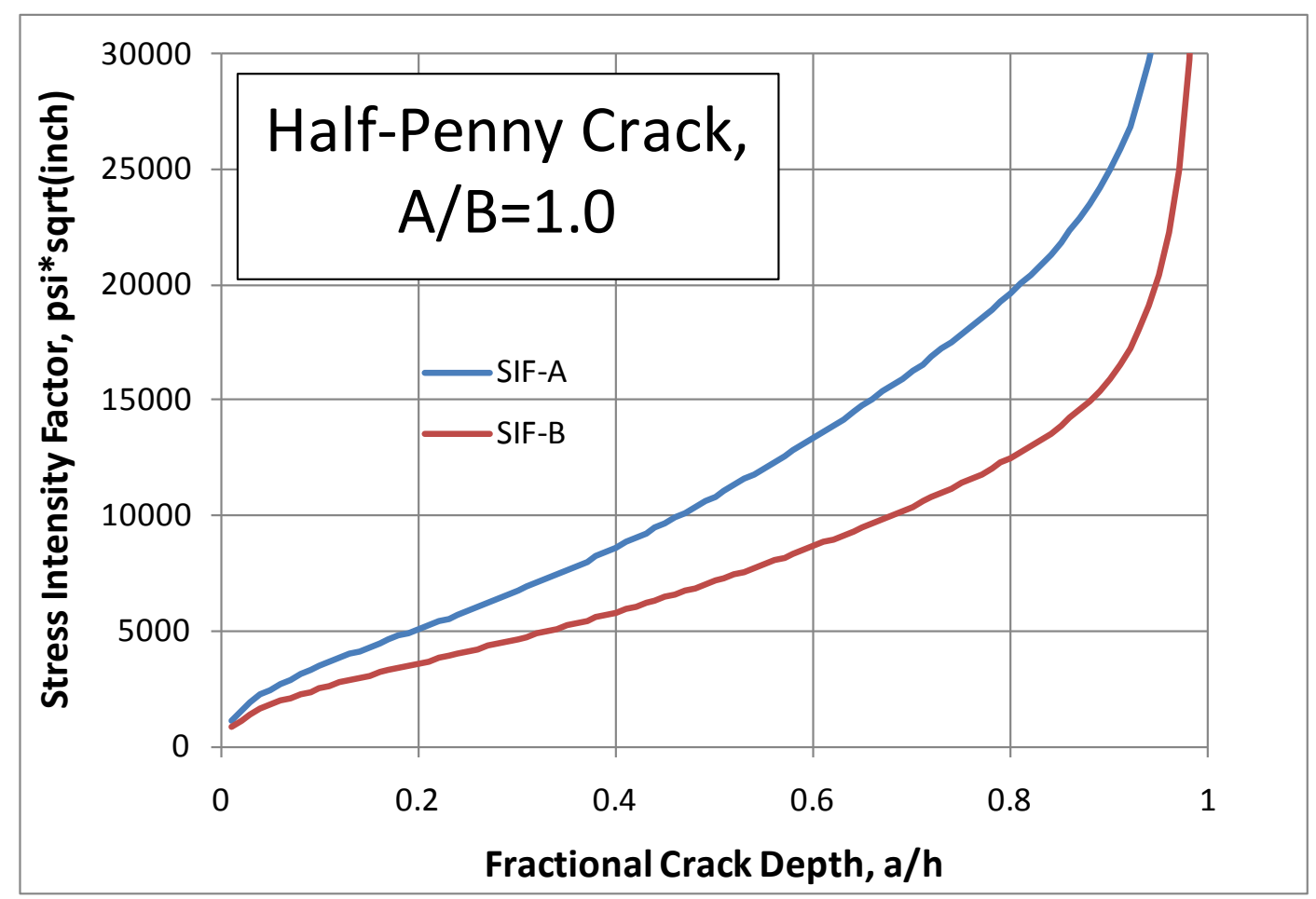

Figure 7. Stress Intensity Factors for Crack Growth in Directions "a" and "b" for the HalfPenny Crack ( $a / b=1.0), h=1.5$ inch, Uniform Stress=4875psi, Bending Stress=488 psi. 
Physics-Based SCC Reliability Model in a Cumulative Damage Framework

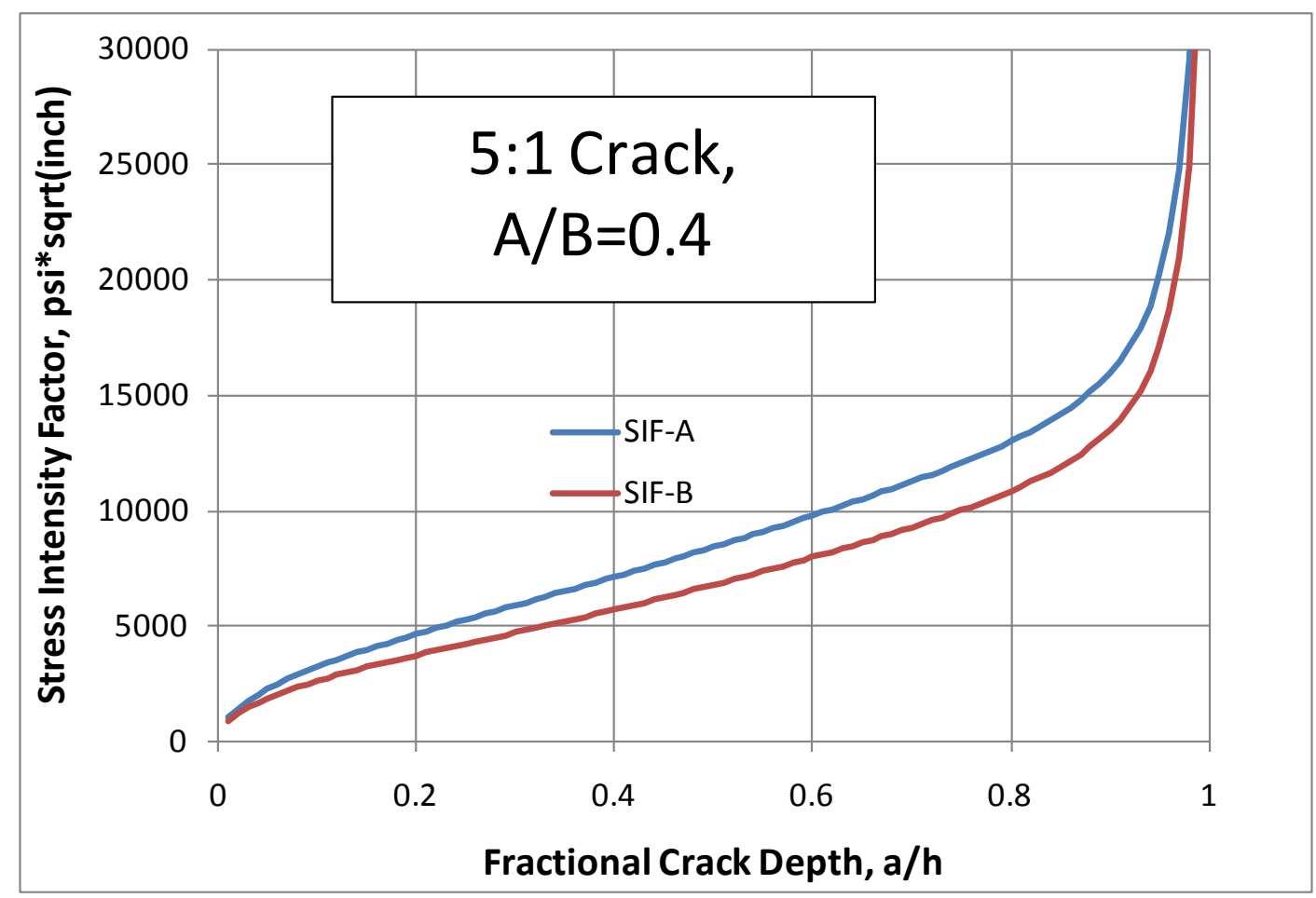

Figure 8. Stress Intensity Factors for Crack Growth in Directions "a" and "b" for the 2.5:1 Crack $(a / b=0.4), h=1.5$ inch, Uniform Stress=4875psi, Bending Stress=488 psi.

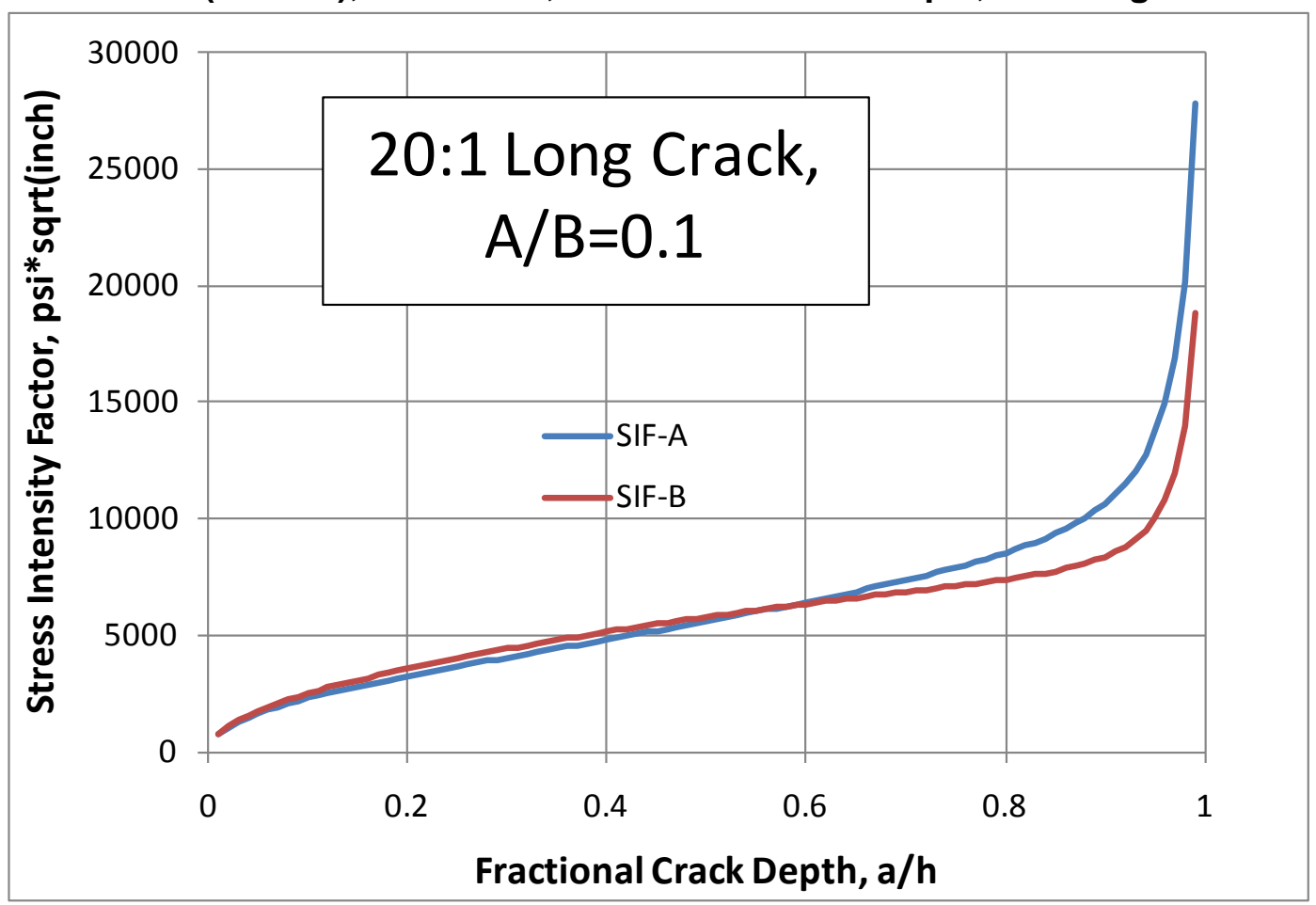

Figure 9. Stress Intensity Factors for Crack Growth in Directions " $a$ " and "b" for the 20:1 Long Crack $(a / b=1.0), h=1.5$ inch, Uniform Stress=4875psi, Bending Stress=488 psi. 
Figure 10 demonstrates how the bending stress affects the calculated stress intensity. A positive $10 \%$ bending stress on the inside of the pipe would act to open the crack which results in a higher $\mathrm{K}_{\mathrm{l}}$ value compared to the uniform stress case. Conversely, a negative $10 \%$ bending stress on the inside of the pipe would act to close the crack. Figure 10 shows that this condition gives a lower $\mathrm{K}_{\mathrm{I}}$ value compared to the uniform stress case.

The Fortran source code used in these calculations is listed at the end of this document. The subroutine, Ki, returns the stress intensity factors, SIFA and SIFB, for crack growth in the "a" and " $b$ " directions, respectively, as a function of the following inputs that define the crack geometry and applied stresses:

$a=$ crack depth

$\mathrm{h}=$ Vessel Wall Thickness

aob = Ratio of crack depth / half-length, $a / b$

sav = uniform stress

$\mathrm{sa}=$ linear stress component at crack depth, a

This configuration should be readily usable to update the stress intensity factor for defining the PWSCC growth rate.

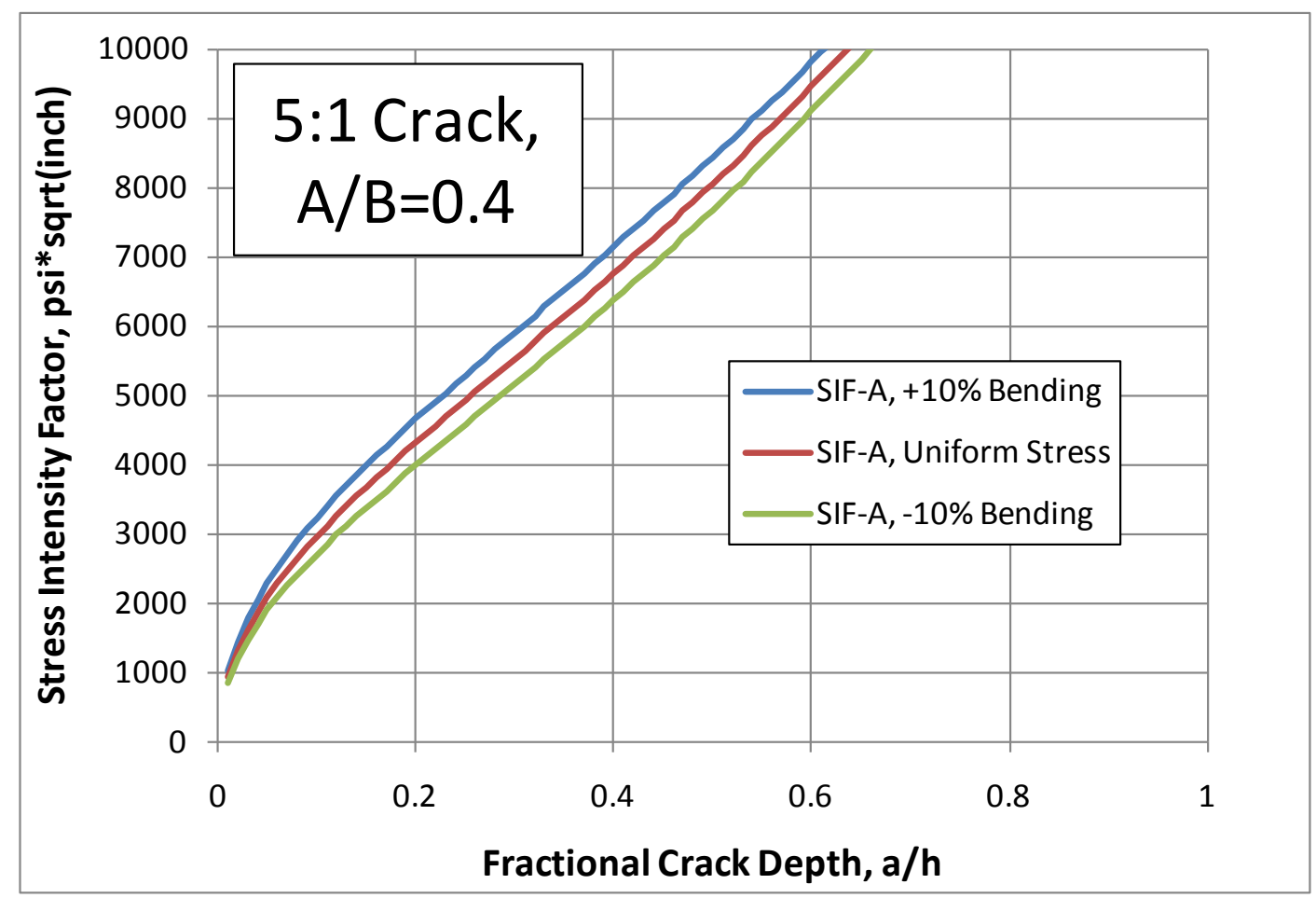

Figure 10. Stress Intensity Factors for a $+/$ - 10\% Range in Bending Stress, 2.5:1 Crack depth $(a / b=0.4), h=1.5$ inch, Uniform Stress=4875psi, Bending Stress $=+\mid-488$ psi. 
Physics-Based SCC Reliability Model in a Cumulative Damage Framework

\section{$\underline{\text { References }}$}

A2.1 Harris, D. O. and D. Dedhia. 1992. Theoretical and User's Manual for pc-PRAISE, A Probabilistic Fracture Mechanics Code for Piping Reliability Analysis. An updated version of NUREG/CR-5864. Engineering Mechanics Technology, Inc. San Jose, California.

A2.2 Rooke, D. P., and D. J. Cartwright. 1976. Compendium of Stress Intensity Factors. ISBN 0117713368 Her Majesty's Stationery Office. London, England.

A2.3 Khaleel, M. A., F. A. Simonen, H. K. Phan, D. O. Harris, and H. Dedhia. 2000. Fatigue Analysis of Components for 60-Year Plant Life. NUREG/CR-6674, PNNL-13227. Pacific Northwest National Laboratory. Richland, Washington.

A2.4 Anderson, T. L., Thorwald, G., D. J. Revelle, D. A. Osage, Janelle, J. L., M. E. Fuhry. 2002. Development of Stress Intensity Factor Solutions for Surface and Embedded Cracks in API 579. Welding Research Council Bulletin 471. ISBN\#1-58145-478-3. Welding Research Council. New York, New York.

A2.5 Anderson, T. L., Thorwald, G., D. J. Revelle, D. A. Osage, Janelle, J. L., M. E. Fuhry. 2002. Stress Intensity and Crack Growth Opening Area Solutions for Through-Wall Cracks in Cylinders and Spheres. Welding Research Council Bulletin 478. ISBN: 158145-485-6. Welding Research Council. New York, New York. 
C

C Stress Intensity Solutions from the pc-PRAISE code

C KI Johnson 12/16/2010

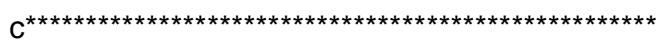

C This program generates a table of stress intensity factors for crack

C growth in the depth 'a' and length'b' directions for a uniform stress,

C sav, and linear stress, sa, at crack depth, a.

C The uniform stress is for axial stress in a pipe that would act to open

C a circumferential part-through-wall crack.

c

C Subroutine Ki returns:

C SIFA = Stress intensity factor for crack growth in the depth, a, direction

C SIFB = Stress intensity factor for crack growth in the length, b, direction

$\mathrm{c}$ a $=$ crack depth

$\mathrm{c} \mathrm{h}=$ Vessel Wall Thickness

c aob = Ratio of crack depth / half-length, $a / b$

c sav = uniform stress

c sa $=$ linear stress component at crack depth, a.

c

c The PC-Praise Ki coefficients are:

c SIFUA = PC-Praise Ki coefficient for uniform stress crack growth, a

c SIFUB = PC-Praise Ki coefficient for uniform stress for crack growth, b

c SIFLA = PC-Praise Ki coefficient for Linear stress for crack growth, a

c SIFLB = PC-Praise Ki coefficient for Linear stress for crack growth, $b$

IMPLICIT DOUBLE PRECISION (A-H,O-Z)

open(unit=10,file='ki-circflaw2.out',status='unknown')

C Estimated Pressurizer Surge Nozzle Dimensions and Pressure

$r=13.0 / 2.0 \quad$ ! inside pipe radius, inch

$\mathrm{h}=(16.0-13.0) / 2.0$ ! pipe wall thickness, inch

Pres $=2250.0$ ! pressure, psi

c Axial Pressure stress

spres $=$ Pres*r/ $/ 2 * h)$

c assume inner-wall axial bending stress component is $+5 \%$ of ave axial stress sbend $=0.10 *$ spres

$\mathrm{c}$ average axial stress for $\mathrm{K}$ solution sav=spres+sbend

c calculate Mode-I Stress Intensity Factors for crack-tips A and B do $50 \mathrm{j}=1,10$

$\mathrm{aob}=\mathrm{j}{ }^{\star} 0.1$

write $(10,501)$ aob

501 format(2x,'AOB = ',f5.2)

write $(10,503) r$, h, pres, spres, sbend, sav

503 format(2x, 'R, H, PRES, Spres, Sbend, Sav',/,

x 3F8.2,3f8.1)

write $(10,502)$

502 format(2x,' AOH, SIFUA, SUFUB, SIFLA, SIFLB,'

$x$,' A, Sav, Sa, SIF-A SIF-B ')

do $100 \mathrm{i}=1,99$

$a=i * 0.01 * h$ 
sa $=-1.0 * a *$ sbend*2/h

CALL Ki(a,h,aob,sav,sa,SIFA,SIFB)

100 continue

50 Continue

Close(10)

STOP

END

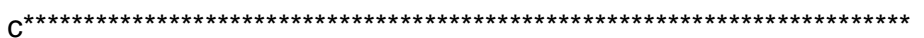

Subroutine Ki(a,h,aob,sav,sa,SIFA,SIFB)

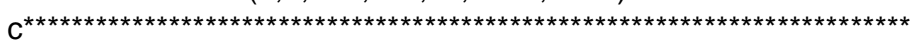

IMPLICIT DOUBLE PRECISION (A-H,O-Z)

$\mathrm{PI}=3.1415927$

SQPI=SQRT(PI)

aoh=a/h

SIFUA = SIFBRA $(A O H, A O B) / S Q P I$

SIFUB $=\operatorname{SIFBRB}(A O H, A O B) / S Q P I$

SIFLA = SFLINA(AOH,AOB) $/$ SQPI

SIFLB $=$ SFLINB $(A O H, A O B) / S Q P I$

c calculate stress intensities for uniform+linear Stress contribution

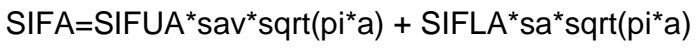

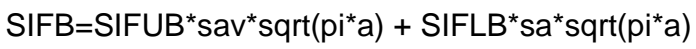

c write out results for checking

write $(10,500)$ AOH,SIFUA,SIFUB,SIFLA,SIFLB,a,sav,sa,SIFA, SIFB

500 format(2x, f5.2,4f10.3,f8.3,4f10.2)

RETURN

END

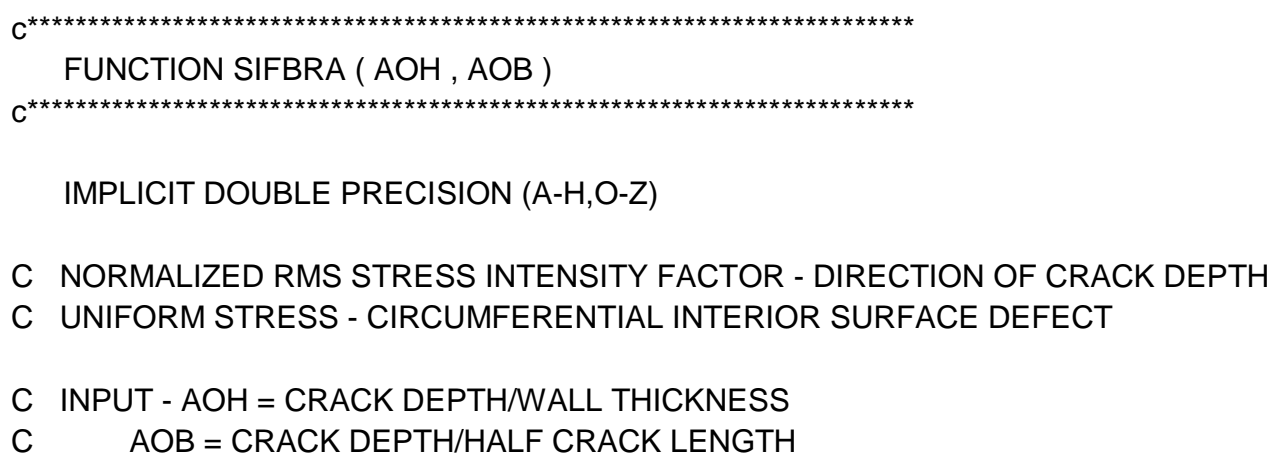


Physics-Based SCC Reliability Model in a Cumulative Damage Framework

C ROUTINE RETURNS KBAR-A / (SIGMA * SQRT (A))

C REVISED COEFFS - CORRECTED FOR SHALLOW CRACKS - LITLIF

DATA D0,D1,D2,D3 / $1.8781,-0.7248,-0.2035,0.2432$ /

DATA E0,E1,E2,E3 / -1.9181，0.4252， $8.0667,-7.4870 /$

DATA F0,F1,F2,F3 / 7.1762 , -11.3209 , -10.4922, 15.9368 /

DATA G0,G1,G2,G3 / -6.0324 , $10.4690,2.0322$, -7.6101 /

$\mathrm{AOHT}=\mathrm{AOH}$

IF(AOH.GE.0.999)AOHT=.999

$\mathrm{AOBT}=\mathrm{AOB}$

IF(AOB.GE.0.999)AOBT $=.999$

$\mathrm{DD}=\mathrm{D} 0+\mathrm{AOBt}^{*}\left(\mathrm{D} 1+\mathrm{AOBt}^{*}\left(\mathrm{D} 2+\mathrm{AOBt}^{*} \mathrm{D} 3\right)\right)$

$E E=E 0+A O B t^{*}\left(E 1+A O B t^{*}\left(E 2+A O B t^{*} E 3\right)\right)$

$\mathrm{FF}=\mathrm{F0}+\mathrm{AOBt}^{\star}\left(\mathrm{F} 1+\mathrm{AOBt}^{\star}\left(\mathrm{F} 2+\mathrm{AOBt}^{\star} \mathrm{F} 3\right)\right)$

$\mathrm{GG}=\mathrm{G} 0+\mathrm{AOBt}^{\star}\left(\mathrm{G} 1+\mathrm{AOBt}^{\star}\left(\mathrm{G} 2+\mathrm{AOBt}^{\star} \mathrm{G} 3\right)\right)$

$\operatorname{SIFBRA}=(D D+A O H T *(E E+A O H T$ * $(F F+A O H T$ * GG $))) / S Q R T(1.0-A O H T)$

RETURN

END

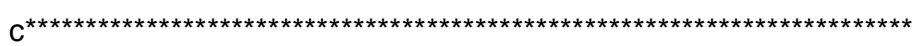

FUNCTION SIFBRB ( $\mathrm{AOH}, \mathrm{AOB})$

$\mathrm{C}^{\star \star \star \star \star \star \star \star \star \star \star \star \star \star \star ~}$

IMPLICIT DOUBLE PRECISION (A-H,O-Z)

C NORMALIZED RMS STRESS INTENSITY FACTOR - DIRECTION OF CRACK LENGTH

C UNIFORM STRESS - CIRCUMFERENTIAL INTERIOR SURFACE DEFECT

C INPUT - AOH = CRACK DEPTH/WALL THICKNESS

C $\quad A O B=$ CRACK DEPTH/HALF CRACK LENGTH

C ROUTINE RETURNS KBAR-B / (SIGMA * SQRT (A))

C CORRECTED FOR SHALLOW CRACKS SEPT 1982-LITLIF

DATA D0,D1,D2,D3 / $1.3003,0.1046,-0.1943,0.03935$ /

DATA E0,E1,E2,E3 / -1.3745, $0.7675,-1.3837,1.5430 /$

DATA F0,F1,F2,F3 / $4.0255,-7.0179,10.6008,-7.7883$ /

DATA G0,G1,G2,G3 / -3.2410 , $5.3097,-7.8403,5.4374$ /

$\mathrm{AOHT}=\mathrm{AOH}$

IF(AOH.GE.0.999)AOHT=.999

$\mathrm{AOBT}=\mathrm{AOB}$

IF(AOB.GE.0.999)AOBT $=.999$

$\mathrm{DD}=\mathrm{D} 0+\mathrm{AOBt}^{\star}\left(\mathrm{D} 1+\mathrm{AOBt}^{\star}\left(\mathrm{D} 2+\mathrm{AOBt}^{\star} \mathrm{D} 3\right)\right)$

$E E=E 0+A O B t^{\star}\left(E 1+A O B t^{\star}\left(E 2+A O B t^{\star} E 3\right)\right)$

$F F=F 0+A O B t^{*}\left(F 1+A O B t^{*}\left(F 2+A O B t^{*} F 3\right)\right)$

$\mathrm{GG}=\mathrm{G} 0+\mathrm{AOBt}^{*}\left(\mathrm{G} 1+\mathrm{AOBt}^{\star}\left(\mathrm{G} 2+\mathrm{AOBt}^{\star} \mathrm{G} 3\right)\right)$

$\operatorname{SIFBRB}=(D D+A O H T *(E E+A O H T$ * $(F F+A O H T$ * GG $))) / S Q R T(1.0-A O H T)$

RETURN

END

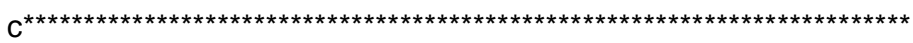


Physics-Based SCC Reliability Model in a Cumulative Damage Framework

END 